\title{
Measuring the Volatility in U.S. Treasury Benchmarks and Debt Instruments*
}

\author{
Suhejla Hoti \\ School of Economics and Commerce \\ University of Western Australia \\ Esfandiar Maasoumi \\ Southern Methodist University \\ Michael McAleer \\ School of Economics and Commerce \\ University of Western Australia \\ Daniel Slottje \\ Department of Economics \\ Southern Methodist University \\ and \\ FTI Consulting
}

October 2005

* The first and third authors wish to acknowledge the financial support of the Australian Research Council. We thank Vance Martin for help with the GAUSS code.

Contact author: Daniel Slottje, Department of Economics, SMU, Dallas, TX 75275, USA; Tel. 214-768-3555, dslottje@mail.smu.edu. 


\begin{abstract}
As U.S. Treasury securities carry the full faith and credit of the U.S. government, they are free of default risk. Thus, their yields are risk-free rates of return, which allows the most recently issued U.S. Treasury securities to be used as a benchmark to price other fixedincome instruments. This paper analyzes the time series properties of interest rates on U.S. Treasury benchmarks and related debt instruments by modelling the conditional mean and conditional volatility for weekly yields on 12 Treasury Bills and other debt instruments for the period 8 January 1982 to 20 August 2004. The conditional correlations between all pairs of debt instruments are also calculated. These estimates are of interest as they enable an assessment of the implications of modelling conditional volatility on forecasting performance. The estimated conditional correlation coefficients indicate whether there is specialization, diversification or independence in the debt instrument shocks. Constant conditional correlation estimates of the standardized shocks indicate that the shocks to the first differences in the debt instrument yields are generally high and always positively correlated. In general, the primary purpose in holding a portfolio of Treasury Bills and other debt instruments should be to specialize on instruments that provide the largest returns. Tests for Stochastic Dominance are consistent with these findings, but find somewhat surprising rankings between debt instruments with implications for portfolio composition. 30 year treasuries, Aaa bonds and mortgages tend to dominate other instruments, at least to the second order.
\end{abstract}

Key words and phrases: Treasury bills, debt instruments, risk, conditional volatility, conditional correlation, asymmetry, specialization, diversification, independence, forecasting. 


\section{Introduction}

This paper measures and analyzes the conditional volatility of U.S. Treasury "benchmarks" and other debt instruments. Although the volatility in U.S. Treasuries has been analyzed previously in the literature, this paper focuses on the conditional volatility in U.S. Treasuries using a multivariate conditional volatility model that analyzes the correlations across debt instruments. Bollerslev et al. (2000), Maheu and McCurdy (2002), Andersen et al. (2003), Ball and Torous (2003), Bansal and Zhou (2003), CollinDufresne and Goldstein (2003), Ritchken and Trevor (2003), Scruggs (2003), and Kalimipalli and Susmel (2004) have examined volatility in different applications, but there has generally been very limited analysis of a few Treasuries. Balduzzi et al. (1998) noted a stochastic "central tendency" in bond yields, which they argued could be approximated by a linear combination of longer term rates. Volatility in stock returns has been analyzed rigorously in the literature. For example, Glosten et al. (1992), Maheu and McCurdy (2000), Doukas et al. (2003) Dumas et al. (2003), Fleming et al. (2003), Johnson (2003), Liesenfeld and Richard (2003), Odean (2003), and Thomakos and Wang (2003) have examined volatility in stock returns. However, Treasuries have received considerably less scrutiny.

Business economists, macroeconomic model builders, policy analysts, financial analysts, investment bankers and others practitioners rely on U.S. Treasury benchmarks as accurate instruments of relatively risk-free interest rates in their forecast models (see, for example, Ho and Lee (2004) and Brealy and Myers (2004) for practical applications). The pressure that analysts face in their forecasts has been analyzed carefully (see, for example, Hong and Kubik (2003) and Sharpe (2002)). In addition, thousands of financial transactions are consumated annually, involving billions of dollars based on net present value calculations that rely on forecasted U.S. Treasury benchmark interest rates (see, for example, Fleming (2000) and Fabozzi (2001)). These transactions include calculating discounted cash flows, the net present value of financial contracts, and lost future profits and earnings. It is important to understand the time series properties of these benchmarks as they are widely forecasted, and such forecasts are used extensively in economics, finance and 
litigation. If the volatility of the Treasury benchmarks is not specified carefully, the resulting model will yield biased volatility estimates and misleading benchmark forecasts (see Christoffersen and Diebold (2000), Bollerslev and Wright (2001), Daniel et al. (2003), Ferson et al. (2003), Johnson (2003) and Odean (2003) for discussions of financial model misspecification).

The world is changing rapidly. In early 2001, significant concern arose because countries with advanced economies were consolidating budget surpluses, and this movement had significant ramifications for government securities markets. The International Monetary Fund, the U.S. Federal Reserve Bank, the Bank for International Settlements and other institutions were gravely concerned that the movement towards budget surpluses would cause the supply of U.S. Treasury securities to shrink, or disappear altogether (see Schinasi et al. (2001) and Fleming (2000, 2001)). A 1999 Congressional Budget Office (CBO) study projected budget surpluses in the USA to continue for 10 years. The U.S. Treasury led this movement as it stopped selling 3-year, 4-year and 7-year Treasury notes, as well as 15-year and 20-year Treasury bonds. The Treasury also issued some notes and bonds less frequently. In 1999, the public held a stock of U.S. Treasuries of \$3.6 trillion, the expectation being that this stock would decline (see Treasury Bulletin, September 2004, Table FD-1, Summary of Federal Debt, www.fms.treas.gov).

The reason for the concern in the late 1990s and well into 2001 was the fact that on-therun (or the most recently issued) U.S. Treasury securities are, in fact, "benchmarks" (see Fabozzi (2001)). As U.S. Treasury securities carry the full faith and credit of the U.S. government, they are free of default risk, and hence their yields are risk-free rates of return. This risk-free status allows U.S. Treasury securities to be used as a benchmark to price other fixed income instruments, and as a hedging tool for other relatively more risky instruments. As Mark Werner of JP Morgan noted in 1998: "The benchmark status not only enhances the overall demand for Treasuries, but also may be vital for the efficient functioning of markets such as Corporate Bonds, Federal Agency Securities, Mortgage Backed Securities, and Interest Rate Swaps. All of these trade at a spread relative to U.S. Treasuries. In making financing decisions, Treasury officials must consider factors such 
as these that potentially impact these closely linked dollar denominated capital markets." (Testimony of Mark Werner, House Way and Means Committee, U.S. Congress, 6-2498). Fixed rate corporate debt issues are typically marketed and sold based on the yield spread of a particular Treasury security (see Fleming (2000), Lane (1999) and Duffee (2003)). Dealers in other markets are more willing to take relatively risky positions in these markets as they can cover their positions by hedging in Treasuries.

Fleming (2000) also notes that Treasuries are useful as a pricing benchmark because they have certain characteristics, such as the tendency of Treasury prices to be highly correlated with prices in other markets. Treasuries are useful as a hedging benchmark because "a loss in a dealer's long position in mortgage-backed securities, for example, could then be offset by a dealer's short position in Treasuries. Hedges frequently involve taking short positions, so the ability to borrow Treasury securities at a low cost in the repurchase market is important. [The futures market can also be used to take short positions [see Thomakos and Wang (2003).] Finally, Treasury market liquidity is important, as hedgers must be able to buy and sell large Treasury positions quickly with minimal transaction costs.” (Fleming (2000, p. 130)). In this regard, see also O'Hara (2003) and Elton and Green (2003).

Thau (2001) notes that, whenever any financial market becomes turbulent, investors place their money in Treasuries, which is called a "flight to quality." Thau (2001, p. 97) also provides a summary of the "benchmark" nature of U.S. Treasuries, noting that: "Before buying any other fixed income security, you should check out the yield of a Treasury with comparable maturity. Professionals do. Every single debt instrument is priced by professionals off Treasuries." The preceding discussion makes it clear why a disappearing benchmark market was so unsettling to many government officials and investors alike at a time (namely, early 2001) when budget surpluses were expected to be the norm in the USA.

Of course, the events of September 11, 2001 dramatically changed the U.S. economy and those concerns. No one seriously thinks that the U.S. economy will have a budget surplus 
at any time in the near future, from the perspective of late-2004. As of June 2004, over \$4.24 trillion of U.S. Treasuries were held by the public (see Treasury Bulletin, September 2004, Table FD-1, Summary of Federal Debt, www.fms.treas.gov). Treasuries remain important benchmarks for the reasons discussed above. In addition, the on-the-run benchmarks also are widely applied to forecast interest rates, inflation and other economic indicators that have an impact on the U.S. and global economies. For these reasons, it is important to analyze the time series properties of the benchmarks to determine if they are, in fact, a reasonable gauge or instrument for forecasting interest rates and other economic fundamentals.

The plan of the remainder of the paper is as follows. The structural and asymptotic properties of two well known univariate conditional volatility models and a computationally straightforward multivariate constant conditional correlation model are given in Section 2. Section 3 describes the data to be analyzed. The empirical results regarding the conditional volatilities and conditional correlations across the 12 debt instrument weekly yields are presented in Section 4. Finally, Section 5 provides some concluding remarks.

\section{Models of Financial Conditional Volatility}

The purpose of this section is to model the conditional mean, conditional volatility and conditional correlations for weekly yields on 12 debt instruments for the period 8 January 1982 to 20 August 2004. There is a brief discussion of the specification and properties of alternative generalised autoregressive conditional heteroskedasticity (GARCH) models (see Engle (1982) and Bollerslev (1986)), as well as the Constant Conditional Correlation (CCC) GARCH model of Bollerslev (1990), which will be used to estimate the correlations between all pairs of debt instruments. McAleer (2004) provides a discussion of a variety of univariate and multivariate conditional and stochastic volatility models.

Consider the following specification: 


$$
\begin{aligned}
& y_{t}=E\left(y_{t} \mid F_{t-1}\right)+\varepsilon_{t} \\
& \varepsilon_{t}=D_{t} \eta_{t},
\end{aligned}
$$

where $y_{t}=\left(y_{1 t}, \ldots, y_{m t}\right)^{\prime}$ measures the weekly yields for the 12 Treasury Bill and debt instruments, $\eta_{t}=\left(\eta_{1 t}, \ldots, \eta_{m t}\right)^{\prime}$ is a sequence of independently and identically distributed (iid) random vectors that is obtained from standardizing the tourist arrivals shocks, $\varepsilon_{t}$, using the standardization $D_{t}=\operatorname{diag}\left(h_{1 t}^{1 / 2}, \ldots, h_{m t}^{1 / 2}\right), F_{t}$ is the past information available to time $t, m(=12)$ is the number of Treasury Bill and debt instrument weekly yields, and $t=$ 1,..,1181 weekly observations for the period 8 January 1982 to 20 August 2004.

The CCC model assumes that the conditional volatility in the weekly yields of the alternative debt instruments, $h_{i t}, i=1, \ldots, m$, follows a univariate GARCH process, that is,

$h_{i t}=\omega_{i}+\sum_{j=1}^{r} \alpha_{i j} \varepsilon_{i, t-j}^{2}+\sum_{j=1}^{s} \beta_{i j} h_{i, t-j}$

where $\alpha_{i j}$ represents the ARCH effects, or the short-run persistence of shocks to debt instrument $i$, and $\beta_{i j}$ represents the GARCH effects, or the contribution of shocks to debt instrument $i$ to long-run persistence. Although the CCC specification in (2) has a computational advantage over other more general multivariate GARCH models with constant conditional correlations, such as the Vector Autoregressive Moving Average GARCH (VARMA-GARCH) model of Ling and McAleer (2003) and VARMA Asymmetric GARCH (VARMA-AGARCH) model of Hoti, Chan and McAleer (2002), it nevertheless assumes independence of conditional volatility across debt instruments, and hence no spillovers in conditional volatility across alternative debt instruments. Moreover, CCC does not accommodate the possible asymmetric effects on conditional volatility of positive and negative shocks to alternative debt instruments. 
It is important to note that the conditional correlation matrix for the CCC model, $\Gamma$, is assumed to be constant, with the typical element of $\Gamma$ being given by $\rho_{i j}=\rho_{j i}$ for $i, j=$ $1, \ldots, m$. When the correlation coefficient of debt instruments, $\rho_{i j}$, is close to +1 , the purpose in holding a portfolio of Treasury Bills and other debt instruments should be to specialize on instruments that provide the largest returns. However, when the correlation coefficient of debt instrument shocks, $\rho_{i j}$, is close to -1 , the portfolio should concentrate on diversifying the Treasury Bill and debt instrument base rather than concentrating on obtaining the highest returns. Independent Treasury Bills and debt instruments are those pairs of debt instruments with a correlation coefficient, $\rho_{i j}$, close to zero, in which case neither specialization nor diversification in Treasury Bills and debt instruments would be required for optimal management of debt instruments.

When the number of debt instruments is set to $m=1$, such that a univariate model is specified rather than a multivariate model, equations (1)-(2) become:

$$
\begin{aligned}
& \varepsilon_{t}=\eta_{t} \sqrt{h_{t}} \\
& h_{t}=\omega+\sum_{j=1}^{r} \alpha_{j} \varepsilon_{t-j}^{2}+\sum_{j=1}^{s} \beta_{j} h_{t-j},
\end{aligned}
$$

and $\omega>0, \alpha_{j} \geq 0$ for $j=1, \ldots, r$ and $\beta_{j} \geq 0$ for $j=1, \ldots, s$ are sufficient regularity conditions to ensure that uncertainty is defined sensibly, namely $h_{t}>0$. The decomposition in (3) permits the conditional volatility in debt instruments, $\varepsilon_{t}$, to be modelled by $h_{t}$, on the basis of historical data. Using results from Nelson (1990), Ling and Li (1997) and Ling and McAleer (2002a, 2002b), the necessary and sufficient regularity condition for the existence of the second moment of debt instrument shocks, $\varepsilon_{t}$, for the case $r=s=1$ is given by $\alpha_{1}+\beta_{1}<1$. This result ensures that the estimates are statistically adequate, so that a sensible empirical analysis can be conducted. 
Equation (3) assumes that a positive shock $\left(\varepsilon_{t}>0\right)$ to weekly debt instruments has the same impact on conditional volatility, $h_{t}$, as a negative debt instrument shock $\left(\varepsilon_{t}<0\right)$, but this assumption is typically violated in practice. In order to accommodate the possible differential impact on conditional volatility from positive and negative shocks, Glosten, Jagannathan and Runkle (1992) proposed the following specification for $h_{t}$ :

$h_{t}=\omega+\sum_{j=1}^{r}\left(\alpha_{j}+\gamma_{j} I\left(\varepsilon_{t-j}\right)\right) \varepsilon_{t-j}^{2}+\sum_{j=1}^{s} \beta_{j} h_{t-j}$.

When $r=s=1, \omega>0, \alpha_{1} \geq 0, \alpha_{1}+\gamma_{1} \geq 0$ and $\beta_{1} \geq 0$ are sufficient conditions to ensure that conditional volatility is positive, namely $h_{t}>0$. The short-run persistence of positive (negative) weekly debt instrument shocks is given by $\alpha_{1}\left(\alpha_{1}+\gamma_{1}\right)$. Under the assumption that the standardized shocks, $\eta_{t}$, follow a symmetric distribution, the average short-run persistence of debt instrument shocks is $\alpha_{1}+\gamma_{1} / 2$, and the contribution of debt instrument shocks to average long-run persistence is $\alpha_{1}+\gamma_{1} / 2+\beta_{1}$. Ling and McAleer (2002a) showed that the necessary and sufficient regularity condition for the second moment of debt instrument shocks to be finite, and hence for sensible statistical analysis, is $\alpha_{1}+\gamma_{1} / 2+\beta_{1}<1$.

The parameters in equations (1), (3) and (4) are typically obtained by Maximum Likelihood Estimation (MLE) using a joint normal density for the standardized debt instrument shocks, $\eta_{t}$, after the conditional volatility has been modelled. When $\eta_{t}$ does not follow a joint multivariate normal distribution, the parameters are estimated by QuasiMLE (QMLE). The conditional log-likelihood function is given as follows:

$$
\sum_{t=1}^{n} l_{t}=-\frac{1}{2} \sum_{t=1}^{n}\left(\log h_{t}+\frac{\varepsilon_{t}^{2}}{h_{t}}\right)
$$


Ling and McAleer (2003) showed that the QMLE for GARCH(r,s) is consistent if the second moment regularity condition is finite.

Jeantheau (1998) showed that the log-moment regularity condition given by

$E\left(\log \left(\alpha_{1} \eta_{t}^{2}+\beta_{1}\right)\right)<0$

is sufficient for the QMLE to be consistent for the GARCH(1,1) model of conditional volatility, while Boussama (2000) showed that the QMLE is asymptotically normal for $\operatorname{GARCH}(1,1)$ under the same condition. It is important to note that (5) is a weaker regularity condition than the second moment condition, namely $\alpha_{1}+\beta_{1}<1$. However, the log-moment condition is more difficult to compute in practice as it is the expected value of a function of an unknown random variable and unknown parameters.

McAleer et al. (2002) established the log-moment regularity condition for the GJR(1,1) model of uncertainty, namely

$E\left(\log \left(\left(\alpha_{1}+\gamma_{1} I\left(\eta_{t}\right)\right) \eta_{t}^{2}+\beta_{1}\right)\right)<0$,

and showed that it is sufficient for the consistency and asymptotic normality of the QMLE for GJR(1,1). Moreover, the second moment regularity condition, namely $\alpha_{1}+\gamma_{1} / 2+\beta_{1}<1$, is also sufficient for consistency and asymptotic normality of the QMLE for GJR(1,1).

In empirical examples, the parameters in the regularity conditions (5) and (6) are replaced by their respective QMLE, the standardized residuals, $\eta_{t}$, are replaced by the estimated residuals from the GARCH and GJR models of uncertainty, respectively, for $t=1, \ldots, n$, and the expected values in (5) and (6) are replaced by their respective sample means. 


\section{Data Description}

The data to be analyzed include yields on Treasury benchmarks, which are nominal securities at "constant maturity". The yields are calculated by the U.S. Treasury from the daily yield curve for non-inflation-indexed Treasury securities. This curve correlates the yield on a security to its time to maturity, and is based on the closing market bid yields on actively traded Treasury securities in the over-the-counter market. These market yields are calculated from composites of quotations obtained by the Federal Reserve Bank of New York.

In this paper we examine the constant maturity yield values which are obtained from the yield curve at fixed maturities, for 3-month and 6-month Treasury Bills (hereafter, 3m and 6m TB, respectively), and 1-year, 2-year, 3-year, 5-year, 7-year and 10-year Treasury Bills (hereafter, 1y, 2y, 3y, 5y, 7y and 10y TB, respectively) for the period 8 January 1982 to 20 August 2004. As data for 1-month Treasury Bills are available only since 3 August 2001, and for 20-year Treasury Bills only since 1 October 1993, they are not considered in the analysis.

As the Federal Reserve website indicates, "this method provides a yield for a 10-year maturity, for example, even if no outstanding security has exactly 10 years remaining to maturity.” (for further information regarding the yields on fixed maturity Treasury bills, see http://www.federalreserve.gov/releases/h15/data.htm). For purposes of comparison across Treasury benchmarks and debt instruments, the economic performance of Moody’s Aaa (Aaa), Moody’s Baa (Baa), State and Local (S\&L) bonds, and conventional mortgage rates (Mortgages) are also examined.

\section{Empirical Results}

In the section, we provide the estimates for the AR(1) conditional mean and both the GARCH(1,1) and GJR(1,1) conditional volatility models for the 12 Treasury benchmarks and debt instruments for the period 8 January 1982 to 20 August 2004. 
All the estimates of the parameters are obtained using the Berndt, Hall, Hall and Hausman (BHHH) algorithm (see Berndt et al. (1974)) in the EViews 4 econometric software package. Using the RATS 6 econometric software package yielded virtually identical results. Several different sets of initial values have been used in each case, but do not lead to substantial differences in the estimates. Both the asymptotic and the Bollerslev-Wooldridge (1992) robust t-ratios are reported. In general, the robust t-ratios are smaller in absolute value than their asymptotic counterparts.

Descriptive statistics for the 12 debt instrument weekly yields are given in Table 1 . The lowest means are for the 3m and 6m Treasury Bill yields, while the highest are for Baa and Mortgages; the lowest minima are for the 3m, 6m and 1y Treasury Bill yields, while the highest minima are for Aaa, Baa, S\&L bonds and Mortgages; the maxima are reasonably similar, except for the Baa and Mortgages, which are the highest; the standard deviations are reasonably similar; there is positive skewness in all cases, with the lowest being $3 \mathrm{~m}$ Treasury Bill yields and the highest being Aaa, Baa, S\&L bonds and Mortgages; and kurtosis is similar in all cases.

Unit root tests for all series are reported in Table 2. Apart from S\&L bonds, either the ADF or Phillips-Perron test in Table 2 indicates the presence of unit roots in each series. Figure 1 shows the weekly yields for the 12 debt instruments, which are clearly downward sloping with similar non-stationary patterns.

Virtually all of the pairwise correlations were very high in the levels of the weekly yields for the 12 debt instruments (see Table 3), with the lowest being 0.865. In view of the presence of unit roots, this is not particularly surprising.

Descriptive statistics for the first differences in the 12 debt instrument weekly yields are given in Table 4. The means are all similar and close to zero; the minima are all negative, with the highest minima for Mortages and the lowest minima for the 3m Treasury Bill yield; the maxima are all positive, with the lowest maxima for Baa and the highest for the 
3m Treasury Bill yield; the standard deviations are reasonably similar; there is negative skewness in all cases, with the exception of mortgages, and the most heavily skewed are for the 3m, 6m and 1y Treasury Bill yields; and kurtosis varies considerably, with the highest kurtosis for the $3 \mathrm{~m}, 6 \mathrm{~m}$ and $1 \mathrm{y}$ Treasury Bill yields.

Unit root tests for the first differences in all series are reported in Table 5. Both the ADF and Phillips-Perron tests indicate the absence of unit roots in all series. The first differences in the weekly yields for the 12 debt instruments in Figure 2 show substantial variations over time, and are clearly stationary. For purposes of direct comparison, the conditional means and variances of all series will be reported for the first differences in the weekly yields for the 12 debt instruments.

The pairwise correlations are much lower in the first differences of the 12 debt instrument weekly yields than in their levels (see Table 6). These correlations are generally much higher between pairs of Treasury Bill yields as compared with any pairs from Aaa, Baa, S\&L bonds and Mortgages. In particular, the first differences in the $3 \mathrm{~m}$ and $6 \mathrm{~m}$ Treasury Bill yields have much lower correlations with the other 10 instruments.

The sample volatilities of the first differences in the weekly yields for the 12 debt instruments are given in Figure 3. Clustering of volatilities, which clearly changes over time, and some extreme observations are evident in all 12 series.

As each series had a unit root, the AR(1) conditional mean and GARCH(1,1) conditional variance models were estimated in first differences, with the estimates given in Table 7. All 12 data series give satisfactory results for the conditional means and conditional variances. The intercepts are all significant, the short run persistence (that is, the $\alpha$ or $\mathrm{ARCH}$ ) effects are all positive and significant, and the long run persistence (that is, the $\alpha+\beta$ or ARCH $+\mathrm{GARCH})$ effects are all positive, less than one and significant. The short run persistence effect for 3m Treasury Bills is high at 0.319, and is also quite high for $6 \mathrm{~m}$ Treasury Bills, 1y Treasury Bills, S\&L bonds and Mortgages. The log-moment conditions are satisfied for all 12 data series. Thus, even though the second moment 
conditions are not satisfied for 3m and 6m Treasury Bills, the QMLE for all 12 series are consistent and asymptotically normal. This is a positive empirical finding regarding the empirical usefulness of the estimates.

The GJR(1,1) model was also estimated to check for any asymmetry between the positive and negative shocks to the first differences in the 12 debt instrument yields (see Table 8). As the coefficient of asymmetry (that is, $\gamma$ or the GJR effect) is insignificant in all cases, there is little difference between the GARCH(1,1) and GJR(1,1) specifications, with the GARCH $(1,1)$ model being preferred. The estimated GARCH $(1,1)$ volatilities of the first differences in the weekly yields for the 12 debt instruments are given in Figure 4, and clearly capture the time-varying volatility clusters in all 12 series.

Table 9 reports the CCC matrix, and indicates that the shocks to the first differences in the debt instrument yields are generally quite high and always positively correlated. The high correlations between pairs of Treasury Bill yields, particularly the 1y, 2y, 3y, 5y, 7y and 10y Treasury Bills, and also between Aaa and Baa, show that any of these pairs are close substitutes. S\&L bonds have higher conditional correlations than do Mortgages with 5y, 7y and 10y Treasury Bills. Thus, there should be specialization in these debt instruments. Mortgages generally have much lower conditional correlations with the other debt instruments. In particular, S\&L bonds and Mortgages have a relatively low conditional correlation, which would suggest that the markets for these two debt instruments are segmented (or uncorrelated).

\section{Test for Stochastic Dominance}

\subsection{Definition of Stochastic Dominance}

Consider two stationary time series of returns, $R_{i, t}$ and $R_{j, t}, t=1,2, \cdots, T$, with respective cumulative distribution functions (CDFs), $F_{i}(r)$ and $F_{j}(r)$, over the support $r$. The returns are not expected to be iid, but can exhibit some dependency structures in the 
moments of the distribution. The null hypotheses that $R_{i, t}$ stochastically dominates $R_{j, t}$, for various orders, are as follows:

$$
\begin{array}{lc}
H_{0}: \quad \text { (First order) } & F_{i}(r) \leq F_{j}(r) \\
H_{0}: \text { (Second order) } & \int_{0}^{r} F_{i}(t) d t \leq \int_{0}^{r} F_{j}(t) d t \\
H_{0}: & \text { (Third order) } \quad \int_{0}^{r} \int_{0}^{t} F_{i}(s) d s d t \leq \int_{0}^{r} \int_{0}^{t} F_{j}(s) d s d t \\
H_{0}: & \text { (Fourth order) } \quad \int_{0}^{r} \int_{0}^{t} \int_{0}^{s} F_{i}(u) d u d s d t \leq \int_{0}^{r} \int_{0}^{t} \int_{0}^{s} F_{j}(u) d u d s d t,
\end{array}
$$

for all $\mathrm{r}$, with strict inequality for some $\mathrm{r}$. The null hypotheses in this paper are unambiguous as the test for stochastic dominance combines the test that $R_{i, t}$ stochastically dominates $R_{j, t}$ with the reverse ( $j$ over $i$ ). The alternative hypothesis is that there is no stochastic dominance. Mathematically, lower order dominance implies all higher order dominance rankings. In the case of first order dominance, the distribution function of $R_{i, t}$ lies everywhere to the right of the distribution function of $R_{j, t}$, except for a finite number of points where there is strict equality. This implies that for first order stochastic dominance the probability that returns of the $i^{\text {th }}$ asset are in excess of $r$ say, is higher than the corresponding probability associated with the $j^{\text {th }}$ asset

$$
\operatorname{Pr}\left(R_{i, t}>r\right) \geq \operatorname{Pr}\left(R_{j, t}>r\right)
$$

Let $u(\cdot)$ represent a utility function. For First Order Stochastic Dominance (FSD) of $R_{i, t}$ over $R_{j, t}$, expected utility from holding asset $i$ is generally greater than the expected 
utility from holding asset $j$, within the class of utility functions with positive first derivatives

$$
E\left[u\left(R_{i, t}\right)\right] \geq E\left[u\left(R_{j, t}\right)\right] \text {, where } u^{\prime} \geq 0 .
$$

As an example, in the CCAPM model with power utility and lognormality, the relationship between the returns on equity $\left(R_{s, t}\right)$ and bond yields $\left(R_{b, t}\right)$ is

$$
\ln E_{t}\left[\frac{\left(1+R_{s, t+1}\right)}{\left(1+R_{b, t+1}\right)}\right]=\gamma \sigma_{s, c},
$$

where $\gamma$ is the relative risk aversion parameter and $\sigma_{s, c}$ is the covariance between $\ln \left(1+R_{c, t+1}\right)$ and $\ln \left(1+R_{s, t+1}\right)$. The size of the risk premium is a function of $\gamma \sigma_{s, c}$, which constitutes a rightward shift in the empirical distribution of $R_{s, t+1}$ relative to the distribution of $R_{b, t+1}$, for $\gamma \sigma_{s, c}>0$.

For Second Order Stochastic Dominance (SSD), we require positive first derivatives and negative second derivatives $u^{\prime} \geq 0, u^{\prime \prime} \leq 0$. This reflects risk aversion so that a risk premium is needed to compensate investors for holding assets with relatively higher “volatility”. Third Order Stochastic Dominance (TSD) is defined over utility functions with $u^{\prime} \geq 0, u^{\prime \prime} \leq 0, u^{\prime \prime} \geq 0$. Such agents increasingly prefer positively skewed returns as they are prepared to trade-off lower average returns for the chance of an extreme positive return; see Ingersoll (1987).

Fourth order Stochastic Dominance (FOSD) incorporates the fourth moment of the returns distribution. For fourth order stochastic dominance of asset $i$ over asset $j$, the expected utility from holding asset $i$ is generally greater than the expected utility from 
holding asset $j$, for all utility functions with $u^{\prime} \geq 0, u^{\prime \prime} \leq 0, u^{\prime \prime \prime} \geq 0, u^{\prime \prime \prime \prime} \leq 0$. This class of agents is adverse to assets that exhibit extreme negative as well as positive returns. As agents prefer thin-tailed distributions to fat-tailed distributions, to hold assets that exhibit the latter property they need to be compensated with higher average returns. Even where two assets exhibit the same volatility, the asset returns distributions may nevertheless exhibit differing kurtosis resulting in a risk premium between the two assets.

The approach for conducting stochastic dominance tests is based on the methodology of Linton, Maasoumi and Whang (2005), who propose nonparametric tests of stochastic dominance by using subsampling to construct p-values, as well as recentered bootstrap methods. An important advantage of this approach is that it can accommodate the general dependence structures observed in returns that arise from conditional volatility and higher order moments (Harvey and Siddique (2000)), as well as the observed contemporaneous correlations amongst assets.

\subsection{First Order}

We combine the empirical versions of two tests. The first statistic is for the null hypothesis that $R_{i, t}$ first order dominates $R_{j, t}$

$$
S D_{1, i, j}=\sqrt{T} \sup _{r}\left(F_{i}(r)-F_{j}(r)\right)
$$

while the second statistic is for the reverse test that $R_{j, t}$ first order stochastically dominates $R_{i, t}$

$$
S D_{1, j, i}=\sqrt{T} \sup _{r}\left(F_{j}(r)-F_{i}(r)\right)
$$


$T$ is the sample size, and $\hat{F}_{k}(r)$ is the empirical cumulative distribution functions (CDF) of $R_{k, t}, k=i, j$,

$$
F_{k}(r)=\frac{1}{T} \sum_{t=1}^{T} I\left(R_{k, t} \leq r\right)
$$

where

$$
I\left(R_{k, t} \leq r\right)= \begin{cases}1: & R_{k, t} \leq r \\ 0: & R_{k, t}>r\end{cases}
$$

is the indicator function. Each statistic is an extension of the Kolmogorov-Smirnov test which equals the maximum distance between the two empirical CDFs, $\hat{F}_{i}(r)$ and $\hat{F}_{j}(r)$. The statistics in (5)-(6) are combined to provide an unambiguous overall test of first order stochastic dominance (SD)

$$
M F_{1}=\min _{i \neq j}\left(S D_{1, i, j}, S D_{1, j, i}\right)
$$

Suppose that the null is true so the distribution function of $R_{i, t}$ lies to the right of the distribution function of $R_{j, t}$, apart from at the tails where it is zero. Under the null of stochastic dominance, it must be that $M F_{1} \leq 0$. Under the alternative the empirical CDFs must cross, resulting in $M F_{1}>0$. In this case the assets are maximal, that is, they are unrankable. Such debt instruments would be appropriately priced by the market and any premium simply reflects the price of bearing higher risk, or longer maturity.

For the case where the data exhibit some dependence, the form of the (asymptotic) sampling distribution of the test statistic is generally unknown and depends on the unknown, underlying distributions. To circumvent this problem the sampling distribution 
of the test statistics is approximated using a resampling scheme based on subsampling and bootstrap methods; see Linton, Maasoumi and Whang (2005). The approach is to sample pairs of overlapping sub-periods of the data. By sampling the data in blocks, this captures the dependence structure in the data, whilst sampling the data in paired blocks preserves its contemporaneous structure. The sampling distribution is constructed by computing the test statistics for each sampled block and constructing the p-values from the empirical distributions. In the case where unique blocks are sampled the approach is called sub-sampling, whereas the approach is called bootstrapping where non-unique blocks are sampled and stacked to reconstruct a sample of size $T$.

To test for higher orders of SD, the CDFs are replaced by the integrated CDFs. The corresponding test statistics of higher order SD are denoted as $S D_{m, i, j}, S D_{m, j, i}$ and $M F_{m}$.

\subsection{Results}

\section{Graph of 10 Year vs. Mortgages CDFs (green and broken blue)}

First order dominance in the sample is suggested. The following table provides tests and degrees of confidence.

Table 1: 10 Year vs. Mortgages (Subsampling) 
Block size $=144$; No. of overlapping blocks $=1131$; No. of replications $=1131$

Test for First Order SD (1OSD)

$* * * * * * * * * * * * * * * * * * * * * * * * * * * * * * * * * * * * * * * * * * * * * * * *$

Statistic Bottom(5\%) Top(5\%) PV

McFadden test (1OSD)

$$
-2.157 \quad-11.417 \quad-2.000 \quad 0.081
$$

H0: f does 1OSD g

$$
11.459 \quad 6.167 \quad 11.750 \quad 0.187
$$

H0: g does 1OSD $\mathrm{f}$

$$
-2.157 \quad-11.417 \quad-2.000 \quad 0.081
$$

Test for Second Order SD (2OSD)

$* * * * * * * * * * * * * * * * * * * * * * * * * * * * * * * * * * * * * * * * * * * * * * * * *$

McFadden test (2OSD)

$$
-5.351 \quad-11.750 \quad-3.500 \quad 0.161
$$

H0: $\mathrm{f}$ does 2OSD g

$$
\begin{array}{llll}
13986.274 & 592.083 \quad 1677.167 & 0.000
\end{array}
$$

H0: g does 2OSD f

$$
\begin{array}{llll}
-5.351 & -11.750 & -3.500 & 0.161
\end{array}
$$

Mortgages FSD 10 year yields, which implies all higher orders of SD.

\section{Graph of 30 Year and Aaa CDFs (Green and broken blue)}

\section{Table 2: $\quad 30$ Year vs. Aaa (Subsampling)}


Block size $=136$; No of overlapping blocks $=1020=$ Replications

Test for First Order SD (1OSD)

$* * * * * * * * * * * * * * * * * * * * * * * * * * * * * * * * * * * * * * * * * * * * * * * *$

Statistic Bottom(5\%) Top(5\%) PV

McFadden test (1OSD)

$\begin{array}{llll}-0.500 & -8.146 & 0.171 & 0.202\end{array}$

H0: $f$ does 1 OSD g

$\begin{array}{llll}7.680 & 3.601 & 10.118 & 0.277\end{array}$

H0: g does 1OSD $\mathrm{f}$
$-0.500$
$-8.146$
0.171
0.202

Test for Second Order SD (2OSD)

$* * * * * * * * * * * * * * * * * * * * * * * * * * * * * * * * * * * * * * * * * * * * * * * * *$

McFadden test (2OSD)

$$
\begin{array}{llll}
-6.621 & -9.861 & -0.857 & 0.815
\end{array}
$$

H0: $f$ does 2OSD g

$$
\begin{array}{llll}
6454.586 & 176.129 & 1264.116 & 0.000
\end{array}
$$

H0: g does 2OSD $\mathrm{f}$

$$
\begin{array}{llll}
-6.621 & -9.861 & -0.857 & 0.815
\end{array}
$$

Clearly, Aaa is at least second order dominant over 30 year treasury, implying higher orders of SD.

Graph of 10 year and 30 year CDFs (green and broken blue) 


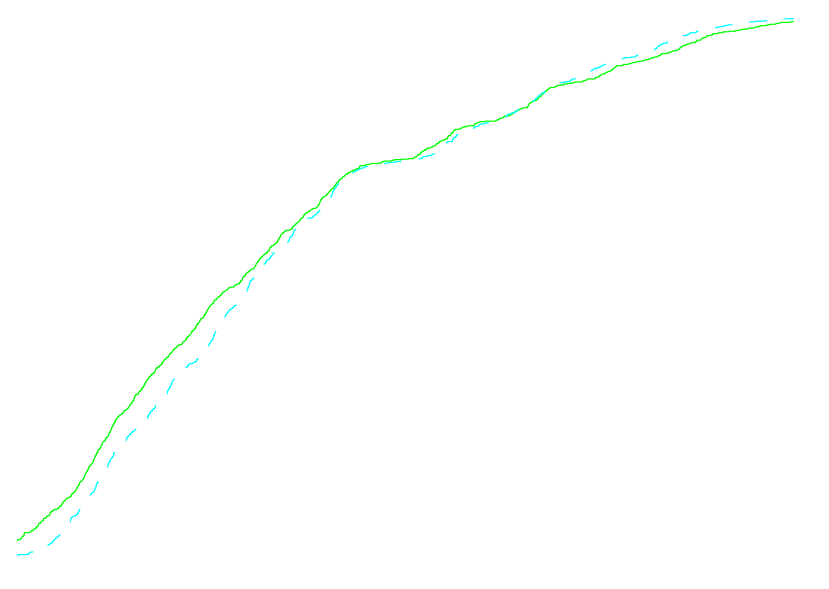

Table 3: 10 Year vs. 30 Year (Subsampling)

Block size $=136$; No. of overlapping blocks $=1020=$ No. of replications; 1155 obs to 2002.

Test for FSD (10SD)

$* * * * * * * * * * * * * * * * * * * * * * * * * * * * * * * * * * * * * * * * * * * * * * * *$

Statistic Bottom(5\%) Top(5\%) PV

McFadden test (1OSD)

$$
0.824 \quad-1.458 \quad 0.857 \quad 0.137
$$

H0: f does 1OSD g

$$
2.501 \quad 0.772 \quad 3.944 \quad 0.395
$$

H0: $g$ does 1OSD $\mathrm{f}$

$$
\begin{array}{llll}
0.824 & -1.458 \quad 2.229 & 0.231
\end{array}
$$

Test for Second Order SD (2OSD)

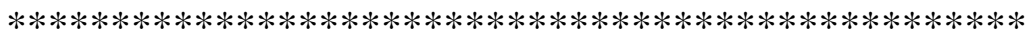

McFadden test (2OSD)

$$
\begin{array}{llll}
-0.942 & -2.830 & 11.405 & 0.359
\end{array}
$$

H0: $\mathrm{f}$ does 2OSD g

$$
1493.823 \quad 10.204 \quad 381.070 \quad 0.000
$$

H0: g does 2OSD f

$$
\begin{array}{llll}
-0.942 & -2.830 \quad 80.347 & 0.359
\end{array}
$$


Test for Third Order SD (3OSD)

McFadden test (3OSD)

$$
\begin{array}{llll}
-0.942 & -2.830 & 123.650 & 0.359
\end{array}
$$

H0: $\mathrm{f}$ does 3OSD g

$$
\begin{array}{llll}
2668022.945 \quad 455.757 & 29828.920 \quad 0.000
\end{array}
$$

H0: g does 3OSD f

$$
\begin{array}{llll}
-0.942 & -2.830 \quad 2442.054 & 0.359
\end{array}
$$

No first order ranking, but second and higher order dominance of 30 year over 10 year is indicated. Given that SD rankings are transitive, Tables 1-3 together suggest that morgages and Aaa dominate 30 year, which dominates 10 year yields. In turn 10 year yields (at least) second order dominate shorter term treasuries. The rankings between shorter term maturities, such as 3 and 6 months, are in much higher orders than 4 order SD, suggesting only very special utility functions and special cisrcumstances and considerations lead agents to hold a particular very short maturity instruments. This pattern is exemplified by the following:

\section{Graph of 3 and 6 months treasury CDFs (green and blue)}

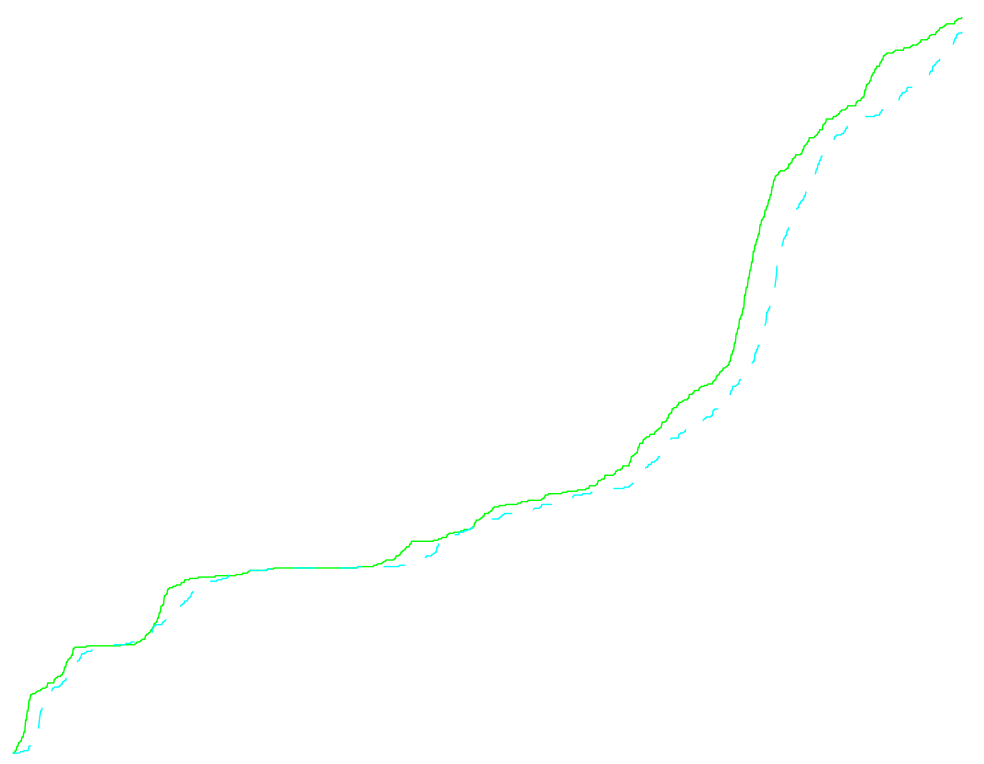

Table 4: 3 vs. 6 months treasuries (subsampling) 
Block size $=96$; NO. of overlapping blocks $=462=$ No. of replications

Test for first order stochastic dominance (1OSD)

***************************************************

Statistic Bottom(5\%) Top(5\%) PV

McFadden test (1OSD)

$$
\begin{array}{llll}
0.085 & -2.245 & 0.306 & 0.361
\end{array}
$$

H0: $f$ does 1 OSD g

$$
\begin{array}{llll}
3.729 & 1.531 & 6.022 & 0.262
\end{array}
$$

H0: $\mathrm{g}$ does 1OSD $\mathrm{f}$

$$
\begin{array}{llll}
0.085 & -2.245 & 0.306 & 0.361
\end{array}
$$

Test for second order stochastic dominance (2OSD)

$* * * * * * * * * * * * * * * * * * * * * * * * * * * * * * * * * * * * * * * * * * * * * * * * *$

McFadden test (2OSD)

$$
\begin{array}{llll}
0.000 & -3.776 & 2.654 & 0.160
\end{array}
$$

H0: $\mathrm{f}$ does 2OSD g

$$
\begin{array}{llll}
701.882 & 8.777 & 447.134 & 0.000
\end{array}
$$

H0: g does 2OSD f

$$
\begin{array}{llll}
0.000 & -3.776 & 2.654 & 0.160
\end{array}
$$

Test for third order stochastic dominance (3OSD)

McFadden test (3OSD)

$$
\begin{array}{llll}
0.000 & -3.776 & 14.085 & 0.117
\end{array}
$$

H0: $\mathrm{f}$ does 3OSD g

$$
\begin{array}{llll}
236750.821 & 153.705 & 23745.966 & 0.000
\end{array}
$$

H0: $\mathrm{g}$ does 3OSD $\mathrm{f}$

$$
\begin{array}{llll}
0.000 & -3.776 & 23.270 & 0.119
\end{array}
$$

Test for fourth order stochastic dominance (4OSD)

$* * * * * * * * * * * * * * * * * * * * * * * * * * * * * * * * * * * * * * * * * * * * * * * * *$

McFadden test (4OSD)

$$
\begin{array}{llll}
0.000 & -3.776 & 2.756 & 0.082
\end{array}
$$

H0: $f$ does 4OSD g 
$68762971.7 \quad 2614.2 \quad 784726.8 \quad 0.000$

H0: g does 4OSD f

$\begin{array}{llll}0.000 & -3.776 & 328.742 & 0.097\end{array}$

There is no tendency for shorter term maturities to dominate any comparable longer term maturity. We do not report similar results to save space, but these are available from the authors.

Overall, it would appear that longer term comparable instruments dominate shorter maturities, and riskier instruments (mortgages and Aaa) dominate treasuries! This is suggestive of superior strategies even when risk-less assets are held as a hedge.

\section{Concluding Remarks}

U.S. Treasury securities are guaranteed by the U.S. government. As there is no default risk, their yields are risk-free rates of return. This risk-free status allows the most recently issues U.S. Treasury securities to be used as a benchmark to price other fixed income instruments, and as a hedging tool for other relatively more risky instruments. Fixed rate corporate debt issues are typically marketed and sold based on the yield spread of a particular Treasury security. Dealers in other markets are more willing to take relatively risky positions in these markets since they can cover their positions by hedging in Treasuries. Moreover, Treasuries are useful as a pricing benchmark because they tend to be highly correlated with prices in other markets, and are also useful as a hedging benchmark.

This paper analyzed the time series properties of interest rates on U.S. Treasury benchmarks and related debt instruments, and modelled the conditional mean and conditional volatility for weekly yields on 12 Treasury Bills and other debt instruments for the period 8 January 1982 to 20 August 2004. The conditional correlations between all pairs of debt instruments were also calculated. These estimates are of interest as they enable an assessment of the implications of modelling conditional volatility on forecasting power. Specifically, when the correlations of debt instruments are close to +1 , the purpose in holding a portfolio of Treasury Bills and other debt instruments should be to specialize on instruments that provide the largest returns. However, when the 
correlations of debt instruments are close to -1 , the portfolio should concentrate on diversifying the Treasury Bill and debt instrument base rather than concentrating on obtaining the highest returns. Independence between Treasury Bills and debt instruments arise when the correlations are close to zero, in which case neither specialization nor diversification would be required for optimal management of debt instruments.

The univariate estimates suggested that conditional volatility models provided an accurate measure of risk in the weekly returns on 12 Treasury benchmarks and related debt instruments. Virtually all of the pairwise correlations were very high in the levels of the weekly yields for the 12 debt instruments, but were much lower in the first differences. The correlations were generally much higher between pairs of Treasury Bill yields as compared with any pairs from Moody's Aaa (Aaa), Moody's Baa (Baa), State and Local (S\&L) bonds, and conventional mortgage rates (Mortgages). In particular, the first differences in the 3-month and 6-month Treasury Bill yields had much lower correlations with the other 10 instruments. The estimated conditional correlation coefficients indicated whether there was specialization, diversification or independence in the debt instrument shocks.

The Constant Conditional Correlation (CCC) estimates of the standardized shocks indicated that the shocks to the first differences in the debt instrument yields were generally quite high and were always positively correlated. The high correlations between pairs of Treasury Bill yields, particularly the 1-year, 2-year, 3-year, 5-year, 7-year and 10-year Treasury Bills, and also between Aaa and Baa, showed that any of these pairs were close substitutes. S\&L bonds had higher conditional correlations than did Mortgages with 5-year, 7-year and 10-year Treasury Bills. Thus, there should be specialization in debt instruments that provide the largest returns. Mortgages generally had much lower conditional correlations with the other debt instruments. In particular, S\&L bonds and Mortgages had a relatively low conditional correlation, which suggested that the markets for these two debt instruments were segmented (or uncorrelated). In such cases, neither specialization nor diversification would be required for optimal management of debt instruments. 


\section{References}

Andersen, T., T. Bollerslev and A. Das (2003), "Variance-ratio statistics and highfrequency data: Testing for changes in intraday volatility patterns”, Journal of Finance, 56, 305-327.

Balduzzi, P. S. Ranjan and S. Foresi (1998), "The central tendency: A second factor in bond yields”, Review of Economics and Statistics, 80, 62-72.

Ball, C. and W. Torous (2003), "The stochastic volatility of short-term interest rates: Some international evidence”, Journal of Finance, 54, 2339-2359.

Bansal, R. and H. Zhou (2003), “Term Structure of Interest Rates with Regime Shifts”, Journal of Finance, 57, 1997-2043.

Berndt, E.K., B.H. Hall, R.E. Hall and J.A. Hausman (1974), "Estimation and inference in nonlinear structural models”, Annals of Economic and Social Measurement, 3, 653-665.

Bollerslev, T. (1986), “Generalised autoregressive conditional heteroscedasticity”, Journal of Econometrics, 31, 307-327.

Bollerslev, T. (1990), "Modelling the coherence in short-run nominal exchange rates: A multivariate generalized ARCH approach”, Review of Economics and Statistics, 72, 498-505.

Bollerslev, T., J. Cai and F. Song (2000), "Intraday periodicity, long memory volatility, and macroeconomic announcement effects in the US Treasury bond market," Journal of Empirical Finance, 7, 37-55

Bollerslev, T. and J.M. Wooldridge (1992), "Quasi-maximum likelihood estimation and inference in dynamic models with time-varying covariances," Econometric Reviews, 11, 143-173.

Bollerslev, T. and J. Wright (2001), "High-Frequency Data, Frequency Domain Inference, and Volatility Forecasting," Review of Economics and Statistics, 83, 596-602.

Boussama, F. (2000), “Asymptotic normality for the quasi-maximum likelihood estimator of a GARCH model”, Comptes Rendus de l'Academie des Sciences, Serie I, 331, 81-84 (in French).

Brealey, R. and S. Myers (2004), Principles of Corporate Finance, 6th Edition, McGrawHill, New York. 
Christoffersen, P. and F. Diebold (2000), "How relevant is volatility forecasting for financial risk management?”, Review of Economics and Statistics, 82, 12-22.

Collin-Dufresne, P. and R. Goldstein (2003), "Do bonds span the fixed income markets? Theory and evidence for unspanned stochastic volatility”, Journal of Finance, 57, $1685-1730$.

Daniel, K., D. Hirshleifer and A. Subrahmanyam (2003), "Investor psychology and security market under- and overreactions”, Journal of Finance, 53, 1839-1885.

Doukas, J., C. Kim and C. Pantzalis (2003), “A test of the errors-in-expectations explanation of the value/glamour stock returns performance: Evidence from analysts' forecasts”, Journal of Finance, 57, 2143-2165.

Duffee, G. (2003), "The relation between Treasury yields and corporate bond yield spreads”, Journal of Finance, 53, 2225-2241.

Dumas, B., J. Fleming and R. Whaley (2003), "Implied volatility functions: Empirical tests”, Journal of Finance, 53, 2059-2106.

Elton, E. and T.C. Green (2003), "Tax and liquidity effects in pricing government bonds”, Journal of Finance, 53, 1533-1562.

Engle, R.F. (1982), “Autoregressive conditional heteroscedasticity with estimates of the variance of United Kingdom inflation”, Econometrica, 50, 987-1007.

Fabozzi, F. (2001), The Handbook of Fixed Income Securities, 6th Edition, McGraw-Hill, New York.

Ferson, W., S. Sarkissian and T. Simin (2003), "Spurious Regressions in Financial Economics?”, Journal of Finance, 58, 1393-1414.

Fleming, J., C. Kirby and B. Ostdiek (2003), “The economic value of volatility timing”, Journal of Finance, 56, 329-352.

Fleming, M. (2000), “The benchmark U.S. Treasury market: Recent performance and possible alternatives”, FRBNY Policy Review, April 2000, pp. 129-145.

Fleming, M. (2001), “Measuring Treasury liquidity,” unpublished paper, FRBNY, June 2001.

Glosten L., R. Jagannathan and D. Runkle (1992), “On the relation between the expected value and volatility of nominal excess return on stock", Journal of Finance, 46, 1779-1801. 
Harvey, C.R. and Siddique, A. (2000). Conditional skewness in asset pricing tests. Journal of Finance, LV, 1263-1295.

Ho, S.Y. and S. Lee (2004), The Oxford Guide to Financial Modeling, Oxford University Press, Oxford.

Hong, H. and J. Kubik (2003), "Analyzing the analysts: Career concerns and biased earnings forecasts”, Journal of Finance, 58, 313-351.

Hoti, S., F. Chan and M. McAleer (2002), "Structure and asymptotic theory for multivariate asymmetric volatility: Empirical evidence for country risk ratings”, invited paper presented to the Australasian Meeting of the Econometric Society, Brisbane, Australia, July 2002.

Ingersoll, J.E. Jr. (1987). Theory and Financial Decision Making. Rowman and Littlefield Studies in Financial Economics: Totowa, New Jersey, USA.

Jeantheau, T. (1998), “Strong consistency of estimators for multivariate ARCH models”, Econometric Theory, 14, 70-86.

Johnson, T. (2003), "Forecast dispersion and the cross section of expected returns," Journal of Finance, 59, 1957-1978.

Kalimipalli, M. and R. Susmel (2004), "Regime-switching stochastic volatility and shortterm interest rates”, Journal of Empirical Finance, 11, 309-329.

Liesenfeld, R. and J.-F. Richard (2003), "Univariate and multivariate stochastic volatility models: Estimation and diagnostics”, Journal of Empirical Finance, 10, 505-531.

Ling, S. and W.K. Li (1997), “On fractionally integrated autoregressive moving-average models with conditional heteroskedasticity”, Journal of the American Statistical Association, 92, 1184-1194.

Ling, S. and M. McAleer (2002a), "Stationarity and the existence of moments of a family of GARCH processes”, Journal of Econometrics, 106, 109-117.

Ling, S. and M. McAleer (2002b), "Necessary and sufficient moment conditions for the GARCH(r,s) and asymmetric power GARCH(r,s) models”, Econometric Theory, 18, 722-729.

Ling, S. and M. McAleer (2003), "Asymptotic theory for a vector ARMA-GARCH model”, Econometric Theory, 19, 278-308.

Linton, O., E. Maasoumi, and Y.J. Whang (2005), "Consistent Testing for Stochastic Dominance: A Subsampling Approach," Review of Economic Studies, 72, 735-765.

Maheu, J. and T. McCurdy (2002), “Nonlinear Features of Realized FX Volatility”, 
Review of Economics and Statistics, 84, 668-681.

Maheu, J. and T. McCurdy (2000), "Volatility dynamics under duration-dependent mixing”, Journal of Empirical Finance, 7, 345-372.

McAleer, M. (2004), "Automated inference and learning in modelling financial volatility”, to appear in Econometric Theory.

McAleer, M., F. Chan and D. Marinova (2002), “An econometric analysis of asymmetric volatility: Theory and application to patents", invited paper presented to the Australasian meeting of the Econometric Society, Brisbane, Australia, July 2002, to appear in Journal of Econometrics.

Nelson, D.B. (1990), "Stationarity and persistence in the $\operatorname{GARCH}(1,1)$ model", Econometric Theory, 6, 318-334.

Odean, T. (2003), "Volume, volatility, price, and profit when all traders are above average", Journal of Finance, 53, 1887-1934.

O'Hara, M. (2003), "Presidential address: Liquidity and price discovery”, Journal of Finance, 58, 1335-1354.

Ritchken, P. and R. Trevor (2003), "Pricing options under generalized GARCH and stochastic volatility processes," Journal of Finance, 54, 377-402.

Schinasi, G., C. Kramer and R. T. Smith (2001), "Financial implications of the shrinking supply of the U.S. Treasury securities,” International Monetary Fund, March 2001.

Scruggs, J. (2003), "Resolving the puzzling intertemporal relation between the market risk premium and conditional market variance: A two-factor approach", Journal of Finance, 53, 575-603.

Sharpe, S. (2002), "Reexamining stock valuation and inflation: The implications of analysts' earnings forecasts”, Review of Economics and Statistics, 84, 632-648.

Thau, A. (2001), The Bond Book, McGraw-Hill, New York.

Thomakos, D. and T. Wang (2003), "Realized volatility in the futures markets”, Journal of Empirical Finance, 10, 321-353. 
Table 1: Descriptive Statistics for 12 Debt Instrument Weekly Yields, 8 January 1982 to 20 August 2004

\begin{tabular}{c|cccccc}
\hline Instrument & Mean & Minimum & Maximum & SD & Skewness & Kurtosis \\
\hline 3m TB & 5.644 & 0.860 & 14.970 & 2.646 & 0.363 & 3.368 \\
6m TB & 5.870 & 0.870 & 15.300 & 2.760 & 0.416 & 3.419 \\
1y TB & 6.096 & 0.950 & 15.110 & 2.803 & 0.454 & 3.345 \\
2y TB & 6.562 & 1.140 & 15.100 & 2.821 & 0.497 & 3.272 \\
3y TB & 6.788 & 1.390 & 15.050 & 2.758 & 0.569 & 3.257 \\
5y TB & 7.123 & 2.130 & 14.910 & 2.635 & 0.708 & 3.242 \\
7y TB & 7.369 & 2.700 & 14.900 & 2.558 & 0.768 & 3.191 \\
10y TB & 7.493 & 3.200 & 14.840 & 2.488 & 0.817 & 3.141 \\
Aaa & 8.612 & 4.840 & 15.490 & 2.168 & 0.967 & 3.405 \\
Baa & 9.648 & 6.060 & 17.290 & 2.476 & 1.118 & 3.626 \\
S\&L & 6.804 & 4.210 & 13.440 & 1.841 & 1.181 & 4.044 \\
Mortgages & 9.227 & 5.210 & 17.660 & 2.637 & 1.025 & 3.591 \\
\hline
\end{tabular}

Note: TB denotes Treasury Bills, $\mathrm{m}$ is month, $\mathrm{y}$ is year, Aaa and Baa are Moody's Aaa and Baa, respectively, S\&L denotes State and Local bonds, and Mortgages are conventional mortgage rates.

Table 2: Unit Root Test Statistics for 12 Debt Instrument Weekly Yields, 8 January 1982 to 20 August 2004

\begin{tabular}{c|cc}
\hline Instrument & ADF & Phillips-Perron \\
\hline 3m TB & -3.8366 & -2.5380 \\
6m TB & -3.6178 & -2.6957 \\
1y TB & -3.5200 & -2.7857 \\
2 y TB & -3.5511 & -2.9124 \\
3y TB & -3.6291 & -3.1206 \\
5y TB & -3.7427 & -3.3708 \\
7y TB & -3.7442 & -3.4597 \\
10y TB & -3.8619 & -3.5382 \\
Aaa & -3.9171 & -3.3228 \\
Baa & -3.4450 & -3.1096 \\
S\&L & -4.5428 & -4.5373 \\
Mortgages & -4.0387 & -3.5424 \\
\hline
\end{tabular}

Note: The simulated critical value at the $1 \%$ level of significance is -3.9709 . 
Table 3: Correlation Coefficients for 12 Debt Instrument Weekly Yields, 8 January 1982 to 20 August 2004

\begin{tabular}{|c|c|c|c|c|c|c|c|c|c|c|c|c|}
\hline Instrument & $3 \mathrm{~m} \mathrm{~TB}$ & $6 \mathrm{~m} \mathrm{~TB}$ & $1 \mathrm{y} \mathrm{TB}$ & $2 \mathrm{y}$ TB & 3y TB & $5 y \mathrm{~TB}$ & $7 \mathrm{y} \mathrm{TB}$ & $10 \mathrm{y}$ TB & Ааa & Baа & S\&L & Mortgages \\
\hline $3 \mathrm{~m}$ TB & 1 & 0.997 & 0.990 & 0.976 & 0.965 & 0.940 & 0.924 & 0.904 & 0.892 & 0.865 & 0.871 & 0.902 \\
\hline $6 \mathrm{~m} \mathrm{~TB}$ & & 1 & 0.997 & 0.987 & 0.977 & 0.955 & 0.940 & 0.921 & 0.908 & 0.882 & 0.888 & 0.918 \\
\hline $1 \mathrm{y} \mathrm{TB}$ & & & 1 & 0.995 & 0.988 & 0.970 & 0.957 & 0.940 & 0.924 & 0.899 & 0.906 & 0.934 \\
\hline $2 y$ TB & & & & 1 & 0.998 & 0.987 & 0.978 & 0.965 & 0.949 & 0.925 & 0.931 & 0.956 \\
\hline 3у ТВ & & & & & 1 & 0.995 & 0.988 & 0.978 & 0.963 & 0.940 & 0.946 & 0.967 \\
\hline $5 y$ TB & & & & & & 1 & 0.998 & 0.994 & 0.981 & 0.961 & 0.966 & 0.980 \\
\hline $7 y$ TB & & & & & & & 1 & 0.998 & 0.988 & 0.970 & 0.975 & 0.984 \\
\hline $10 \mathrm{y}$ TB & & & & & & & & 1 & 0.990 & 0.975 & 0.980 & 0.985 \\
\hline Ааa & & & & & & & & & 1 & 0.993 & 0.989 & 0.993 \\
\hline Ваa & & & & & & & & & & 1 & 0.990 & 0.991 \\
\hline S\&L & & & & & & & & & & & 1 & 0.991 \\
\hline Mortgages & & & & & & & & & & & & 1 \\
\hline
\end{tabular}


Table 4: Descriptive Statistics for the First Differences of 12 Debt Instrument Weekly Yields, 8 January 1982 to 20 August 2004

\begin{tabular}{c|cccccc}
\hline Instrument & Mean & Minimum & Maximum & SD & Skewness & Kurtosis \\
\hline 3m TB & -0.009 & -1.950 & 1.170 & 0.167 & -2.953 & 41.420 \\
6m TB & -0.010 & -1.740 & 0.890 & 0.159 & -2.415 & 27.875 \\
1y TB & -0.010 & -1.600 & 0.630 & 0.150 & -2.144 & 22.523 \\
2y TB & -0.010 & -1.260 & 0.550 & 0.149 & -1.321 & 12.798 \\
3y TB & -0.010 & -1.170 & 0.490 & 0.150 & -0.835 & 8.492 \\
5y TB & -0.009 & -1.060 & 0.440 & 0.146 & -0.599 & 6.978 \\
7y TB & -0.009 & -0.980 & 0.410 & 0.143 & -0.504 & 6.214 \\
10y TB & -0.009 & -0.970 & 0.430 & 0.138 & -0.561 & 6.541 \\
Aaa & -0.008 & -0.660 & 0.480 & 0.101 & -0.403 & 6.496 \\
Baa & -0.009 & -0.680 & 0.350 & 0.091 & -0.441 & 6.706 \\
S\&L & -0.007 & -1.040 & 0.630 & 0.114 & -0.582 & 12.985 \\
Mortgages & -0.010 & -0.400 & 0.840 & 0.110 & 0.651 & 7.041 \\
\hline
\end{tabular}

Table 5: Unit Root Test Statistics for the First Differences of 12 Debt Instrument Weekly Yields, 8 January 1982 to 20 August 2004

\begin{tabular}{c|cc}
\hline Instrument & ADF & Phillips-Perron \\
\hline 3m TB & -14.5903 & -29.0201 \\
6m TB & -13.7661 & -28.4577 \\
1y TB & -12.9853 & -27.0527 \\
2y TB & -12.8115 & -26.5073 \\
3y TB & -12.6121 & -26.7872 \\
5y TB & -12.8121 & -26.6527 \\
7y TB & -12.9840 & -26.8689 \\
10y TB & -13.1212 & -26.8743 \\
Aaa & -12.9947 & -24.8694 \\
Baa & -12.6570 & -23.7320 \\
S\&L & -15.2828 & -26.5752 \\
Mortgages & -12.0803 & -28.4890 \\
\hline
\end{tabular}

Note: The simulated critical value at $1 \%$ level of significance is -2.5675 . 
Table 6: Correlation Coefficients for the First Differences of 12 Debt Instrument Weekly Yields, 8 January 1982 to 20 August 2004

\begin{tabular}{c|cccccccccccc}
\hline Instrument & 3m TB & $6 \mathrm{~m}$ TB & 1y TB & 2y TB & 3y TB & 5y TB & $7 \mathrm{y}$ TB & 10y TB & Aaa & Baa & S\&L & Mortgages \\
\hline 3m TB & 1 & 0.895 & 0.803 & 0.689 & 0.636 & 0.580 & 0.538 & 0.522 & 0.437 & 0.340 & 0.373 & 0.275 \\
6m TB & & 1 & 0.926 & 0.840 & 0.793 & 0.736 & 0.695 & 0.676 & 0.569 & 0.488 & 0.502 & 0.400 \\
1y TB & & & 1 & 0.949 & 0.913 & 0.863 & 0.825 & 0.801 & 0.674 & 0.599 & 0.603 & 0.503 \\
2y TB & & & & 1 & 0.977 & 0.945 & 0.910 & 0.885 & 0.753 & 0.701 & 0.652 & 0.607 \\
3y TB & & & & & 1 & 0.972 & 0.946 & 0.925 & 0.790 & 0.739 & 0.677 & 0.645 \\
5y TB & & & & & & 1 & 0.980 & 0.965 & 0.821 & 0.777 & 0.712 & 0.665 \\
7y TB & & & & & & & 1 & 0.986 & 0.848 & 0.801 & 0.724 & 0.665 \\
10y TB & & & & & & & & 1 & 0.858 & 0.810 & 0.728 & 0.657 \\
Aaa & & & & & & & & & 1 & 0.875 & 0.665 & 0.651 \\
Baa & & & & & & & & & & 1 & 0.641 & 0.696 \\
S\&L & & & & & & & & & & & 1 & 0.524 \\
Mortgages & & & & & & & & & & & & \\
\hline
\end{tabular}


Table 7: GARCH(1,1) Estimates for the First Differences of 12 Debt Instrument Yields, 8 January 1982 to 20 August 2004

\begin{tabular}{|c|c|c|c|c|c|c|c|}
\hline Instrument & $\phi_{1}$ & $\phi_{2}$ & $\omega$ & $\alpha$ & $\beta$ & $\begin{array}{c}\text { Log- } \\
\text { moment }\end{array}$ & $\begin{array}{c}\text { Second } \\
\text { moment }\end{array}$ \\
\hline \multirow[t]{3}{*}{$3 \mathrm{~m}$ TB } & -0.001 & 0.178 & 0.001 & 0.319 & 0.684 & -0.103 & 1.003 \\
\hline & -0.276 & 5.670 & 7.381 & 14.475 & 28.674 & & \\
\hline & -0.243 & 4.806 & 2.604 & 3.696 & 13.297 & & \\
\hline \multirow[t]{3}{*}{$6 \mathrm{~m}$ TB } & -0.003 & 0.239 & $1.2 \mathrm{E}-04$ & 0.164 & 0.848 & -0.021 & 1.013 \\
\hline & -1.363 & 9.034 & 2.876 & 16.035 & 100.693 & & \\
\hline & -1.381 & 5.794 & 2.671 & 2.589 & 16.891 & & \\
\hline \multirow[t]{3}{*}{$1 \mathrm{y} \mathrm{TB}$} & -0.004 & 0.251 & 3.1E-04 & 0.136 & 0.855 & -0.033 & 0.991 \\
\hline & -1.504 & 9.668 & 3.678 & 12.791 & 73.272 & & \\
\hline & -1.260 & 5.654 & 3.070 & 2.833 & 21.889 & & \\
\hline \multirow[t]{3}{*}{$2 y$ TB } & -0.006 & 0.260 & 0.001 & 0.104 & 0.853 & -0.060 & 0.956 \\
\hline & -1.666 & 9.392 & 3.902 & 8.099 & 38.238 & & \\
\hline & -1.397 & 6.390 & 3.000 & 2.350 & 21.912 & & \\
\hline \multirow[t]{3}{*}{ Зу ТВ } & -0.005 & 0.256 & 0.001 & 0.099 & 0.850 & -0.064 & 0.950 \\
\hline & -1.568 & 9.061 & 3.348 & 6.604 & 29.933 & & \\
\hline & -1.366 & 7.123 & 3.091 & 2.793 & 24.522 & & \\
\hline \multirow[t]{3}{*}{$5 y$ TB } & -0.006 & 0.243 & 0.001 & 0.092 & 0.861 & -0.059 & 0.952 \\
\hline & -1.734 & 8.533 & 3.173 & 5.957 & 30.585 & & \\
\hline & -1.508 & 6.861 & 2.866 & 2.928 & 26.002 & & \\
\hline \multirow[t]{3}{*}{ 7y TВ } & -0.006 & 0.225 & 0.001 & 0.081 & 0.882 & -0.045 & 0.963 \\
\hline & -1.880 & 7.659 & 2.878 & 5.586 & 35.937 & & \\
\hline & -1.668 & 6.819 & 2.769 & 3.236 & 32.447 & & \\
\hline \multirow[t]{3}{*}{$10 y$ TB } & -0.006 & 0.227 & 0.001 & 0.090 & 0.872 & -0.048 & 0.962 \\
\hline & -1.859 & 7.865 & 2.822 & 5.717 & 33.173 & & \\
\hline & -1.689 & 6.710 & 2.967 & 3.253 & 31.041 & & \\
\hline \multirow[t]{3}{*}{ Aаa } & -0.005 & 0.314 & $1.1 \mathrm{E}-04$ & 0.062 & 0.926 & -0.017 & 0.988 \\
\hline & -2.085 & 10.971 & 2.923 & 6.648 & 80.604 & & \\
\hline & -2.019 & 10.779 & 2.106 & 3.624 & 50.855 & & \\
\hline \multirow[t]{3}{*}{ Baа } & -0.006 & 0.357 & 4.9E-04 & 0.062 & 0.868 & -0.078 & 0.930 \\
\hline & -2.342 & 12.094 & 2.414 & 3.457 & 19.678 & & \\
\hline & -2.296 & 12.384 & 2.310 & 2.963 & 25.035 & & \\
\hline \multirow[t]{3}{*}{ S\&L } & -0.002 & 0.237 & $1.2 \mathrm{E}-04$ & 0.122 & 0.875 & -0.021 & 0.997 \\
\hline & -0.973 & 7.934 & 3.562 & 8.365 & 68.681 & & \\
\hline & -0.929 & 7.229 & 1.756 & 4.787 & 38.278 & & \\
\hline \multirow[t]{3}{*}{ Mortgages } & -0.010 & 0.229 & 0.002 & 0.199 & 0.638 & -0.235 & 0.837 \\
\hline & -3.429 & 6.643 & 6.008 & 9.420 & 15.423 & & \\
\hline & -3.504 & 7.567 & 2.820 & 2.977 & 6.639 & & \\
\hline
\end{tabular}

Note: The three entries corresponding to each parameter are their estimates, their asymptotic t-ratios and the Bollerslev and Wooldridge (1992) robust t-ratios. 
Table 8: GJR(1,1) Estimates for the First Differences of 12 Debt Instrument Yields, 8 January 1982 to 20 August 2004

\begin{tabular}{|c|c|c|c|c|c|c|c|c|c|}
\hline Instrument & $\phi_{1}$ & $\phi_{2}$ & $\omega$ & $\alpha$ & $\gamma$ & $\beta$ & $\alpha+\gamma / 2$ & $\begin{array}{c}\text { Log- } \\
\text { moment }\end{array}$ & $\begin{array}{l}\text { Second } \\
\text { moment }\end{array}$ \\
\hline \multirow[t]{3}{*}{$3 \mathrm{~m} \mathrm{~TB}$} & $1.0 \mathrm{E}-04$ & 0.173 & 0.001 & 0.331 & -0.060 & 0.701 & 0.301 & -0.076 & 1.002 \\
\hline & -0.040 & 5.530 & 6.972 & 13.639 & -1.877 & 27.831 & & & \\
\hline & -0.040 & 4.641 & 2.614 & 2.191 & -0.424 & 13.781 & & & \\
\hline \multirow[t]{3}{*}{$6 \mathrm{~m} \mathrm{~TB}$} & -0.002 & 0.241 & $1.2 \mathrm{E}-04$ & 0.182 & -0.041 & 0.852 & 0.161 & -0.005 & 1.013 \\
\hline & -0.879 & 8.454 & 2.796 & 13.143 & -2.201 & 97.937 & & & \\
\hline & -1.036 & 6.154 & 2.681 & 1.784 & -0.500 & 16.735 & & & \\
\hline \multirow[t]{3}{*}{$1 \mathrm{y} \mathrm{TB}$} & -0.003 & 0.251 & 3.2E-04 & 0.153 & -0.036 & 0.855 & 0.135 & -0.020 & 0.990 \\
\hline & -0.993 & 8.928 & 3.749 & 10.317 & -1.915 & 71.571 & & & \\
\hline & -1.084 & 5.880 & 2.834 & 2.004 & -0.513 & 22.282 & & & \\
\hline \multirow[t]{3}{*}{$2 \mathrm{y} \mathrm{TB}$} & -0.005 & 0.262 & 0.001 & 0.113 & -0.022 & 0.856 & 0.102 & -0.049 & 0.957 \\
\hline & -1.323 & 8.801 & 3.728 & 7.634 & -1.268 & 36.376 & & & \\
\hline & -1.390 & 6.682 & 2.922 & 1.551 & -0.333 & 23.625 & & & \\
\hline \multirow[t]{3}{*}{ 3у ТВ } & -0.005 & 0.257 & 0.001 & 0.103 & -0.008 & 0.851 & 0.099 & -0.060 & 0.950 \\
\hline & -1.367 & 8.558 & 3.235 & 6.272 & -0.443 & 28.768 & & & \\
\hline & -1.405 & 7.304 & 3.085 & 1.823 & -0.151 & 25.600 & & & \\
\hline \multirow[t]{3}{*}{$5 y$ TB } & -0.006 & 0.245 & 0.001 & 0.097 & -0.013 & 0.862 & 0.090 & -0.053 & 0.952 \\
\hline & -1.480 & 8.131 & 3.092 & 5.787 & -0.662 & 29.239 & & & \\
\hline & -1.497 & 7.060 & 2.855 & 1.935 & -0.251 & 26.965 & & & \\
\hline \multirow[t]{3}{*}{$7 \mathrm{y} \mathrm{TB}$} & -0.006 & 0.227 & 0.001 & 0.086 & -0.010 & 0.882 & 0.081 & -0.041 & 0.963 \\
\hline & -1.647 & 7.349 & 2.892 & 5.345 & -0.543 & 35.010 & & & \\
\hline & -1.658 & 6.979 & 2.706 & 2.153 & -0.231 & 32.595 & & & \\
\hline \multirow[t]{3}{*}{ 10y ТВ } & -0.005 & 0.231 & 0.001 & 0.098 & -0.019 & 0.873 & 0.088 & -0.040 & 0.961 \\
\hline & -1.549 & 7.503 & 2.831 & 5.586 & -0.974 & 32.494 & & & \\
\hline & -1.568 & 6.988 & 2.871 & 2.207 & -0.416 & 31.607 & & & \\
\hline \multirow[t]{3}{*}{ Aaa } & -0.004 & 0.315 & 9.8E-05 & 0.074 & -0.031 & 0.930 & 0.059 & -0.001 & 0.990 \\
\hline & -1.623 & 10.980 & 2.785 & 5.443 & -1.882 & 83.860 & & & \\
\hline & -1.647 & 10.932 & 2.010 & 3.334 & -1.132 & 52.826 & & & \\
\hline \multirow[t]{3}{*}{ Baa } & -0.005 & 0.358 & 4.6E-04 & 0.071 & -0.017 & 0.874 & 0.062 & -0.064 & 0.936 \\
\hline & -2.135 & 11.950 & 2.348 & 3.182 & -1.014 & 20.998 & & & \\
\hline & -2.187 & 12.280 & 2.307 & 2.983 & -0.397 & 25.181 & & & \\
\hline \multirow[t]{3}{*}{ S\&L } & -0.003 & 0.236 & $1.2 \mathrm{E}-04$ & 0.111 & 0.029 & 0.872 & 0.126 & -0.032 & 0.998 \\
\hline & -1.299 & 7.721 & 3.184 & 8.212 & 1.315 & 55.382 & & & \\
\hline & -1.219 & 7.368 & 1.927 & 2.283 & 0.390 & 40.185 & & & \\
\hline \multirow[t]{3}{*}{ Mortgages } & -0.009 & 0.230 & 0.002 & 0.226 & -0.074 & 0.637 & 0.188 & -0.214 & 0.825 \\
\hline & -2.974 & 6.690 & 6.139 & 9.081 & -2.155 & 14.503 & & & \\
\hline & -3.110 & 7.607 & 2.863 & 2.310 & -0.735 & 6.837 & & & \\
\hline
\end{tabular}

Note: The three entries corresponding to each parameter are their estimates, their asymptotic t-ratios and the Bollerslev and Wooldridge (1992) robust t-ratios. 
Table 9: Constant Conditional Correlations (CCC) of Shocks to the First Differences in the Debt Instrument Yields, 8 January 1982 to 20 August 2004

\begin{tabular}{|c|c|c|c|c|c|c|c|c|c|c|c|c|}
\hline Instrument & $3 \mathrm{~m} \mathrm{~TB}$ & $6 \mathrm{~m} \mathrm{~TB}$ & $1 \mathrm{y} \mathrm{TB}$ & $2 \mathrm{y} \mathrm{TB}$ & $3 y$ TB & $5 y$ TB & $7 \mathrm{y} \mathrm{TB}$ & $10 \mathrm{y} \mathrm{TB}$ & Ааa & Ваa & S\&L & Mortgages \\
\hline $3 \mathrm{~m}$ TB & 1 & 0.813 & 0.721 & 0.636 & 0.603 & 0.548 & 0.504 & 0.478 & 0.355 & 0.340 & 0.307 & 0.355 \\
\hline $6 \mathrm{~m} \mathrm{~TB}$ & & 1 & 0.876 & 0.810 & 0.783 & 0.729 & 0.684 & 0.654 & 0.507 & 0.494 & 0.459 & 0.488 \\
\hline $1 \mathrm{y} \mathrm{TB}$ & & & 1 & 0.941 & 0.919 & 0.868 & 0.825 & 0.790 & 0.631 & 0.613 & 0.570 & 0.566 \\
\hline $2 y \mathrm{~TB}$ & & & & 1 & 0.978 & 0.946 & 0.907 & 0.875 & 0.711 & 0.697 & 0.636 & 0.616 \\
\hline Зу ТВ & & & & & 1 & 0.971 & 0.940 & 0.913 & 0.755 & 0.737 & 0.668 & 0.644 \\
\hline $5 y$ TB & & & & & & 1 & 0.977 & 0.959 & 0.795 & 0.776 & 0.707 & 0.668 \\
\hline $7 y$ TB & & & & & & & 1 & 0.983 & 0.837 & 0.813 & 0.728 & 0.684 \\
\hline $10 \mathrm{y} \mathrm{TB}$ & & & & & & & & 1 & 0.852 & 0.823 & 0.733 & 0.681 \\
\hline Aаa & & & & & & & & & 1 & 0.880 & 0.677 & 0.639 \\
\hline Baа & & & & & & & & & & 1 & 0.677 & 0.635 \\
\hline S\&L & & & & & & & & & & & 1 & 0.566 \\
\hline Mortgages & & & & & & & & & & & & 1 \\
\hline
\end{tabular}


Figure 1: Weekly Yields for 12 Debt Instruments
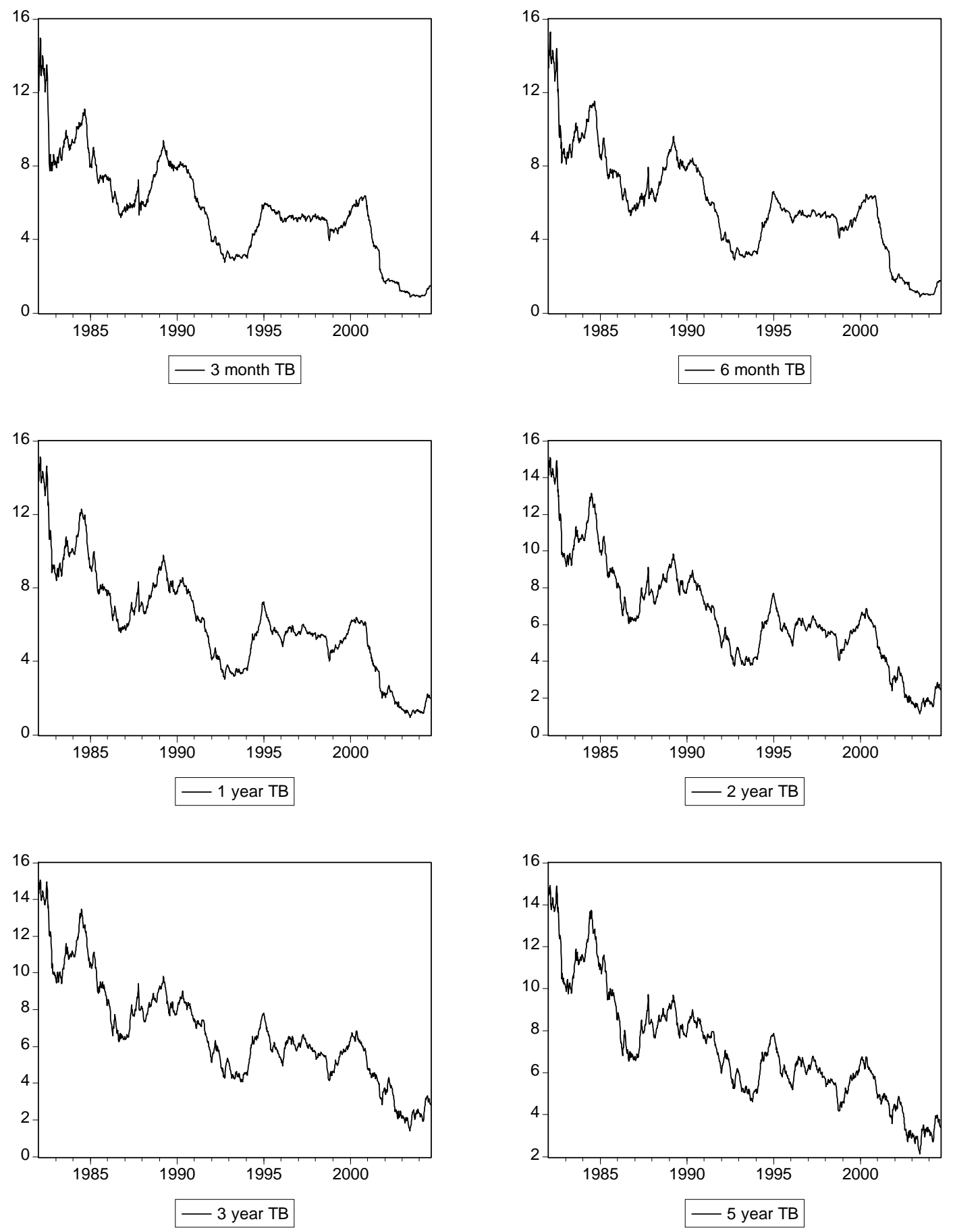
Figure 1: Weekly Yields for 12 Debt Instruments (continued)
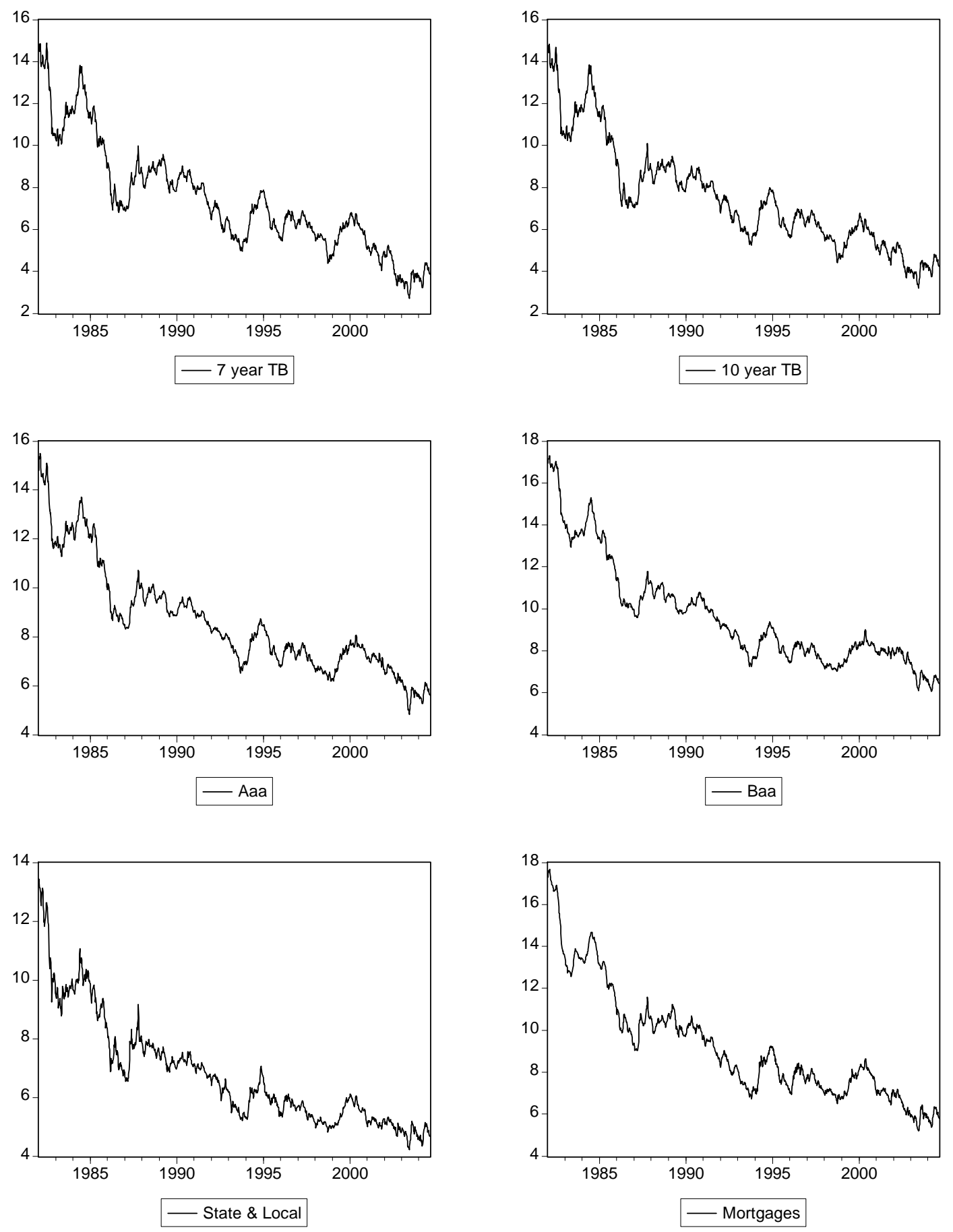
Figure 2: First Differences of Weekly Yields for 12 Debt Instruments
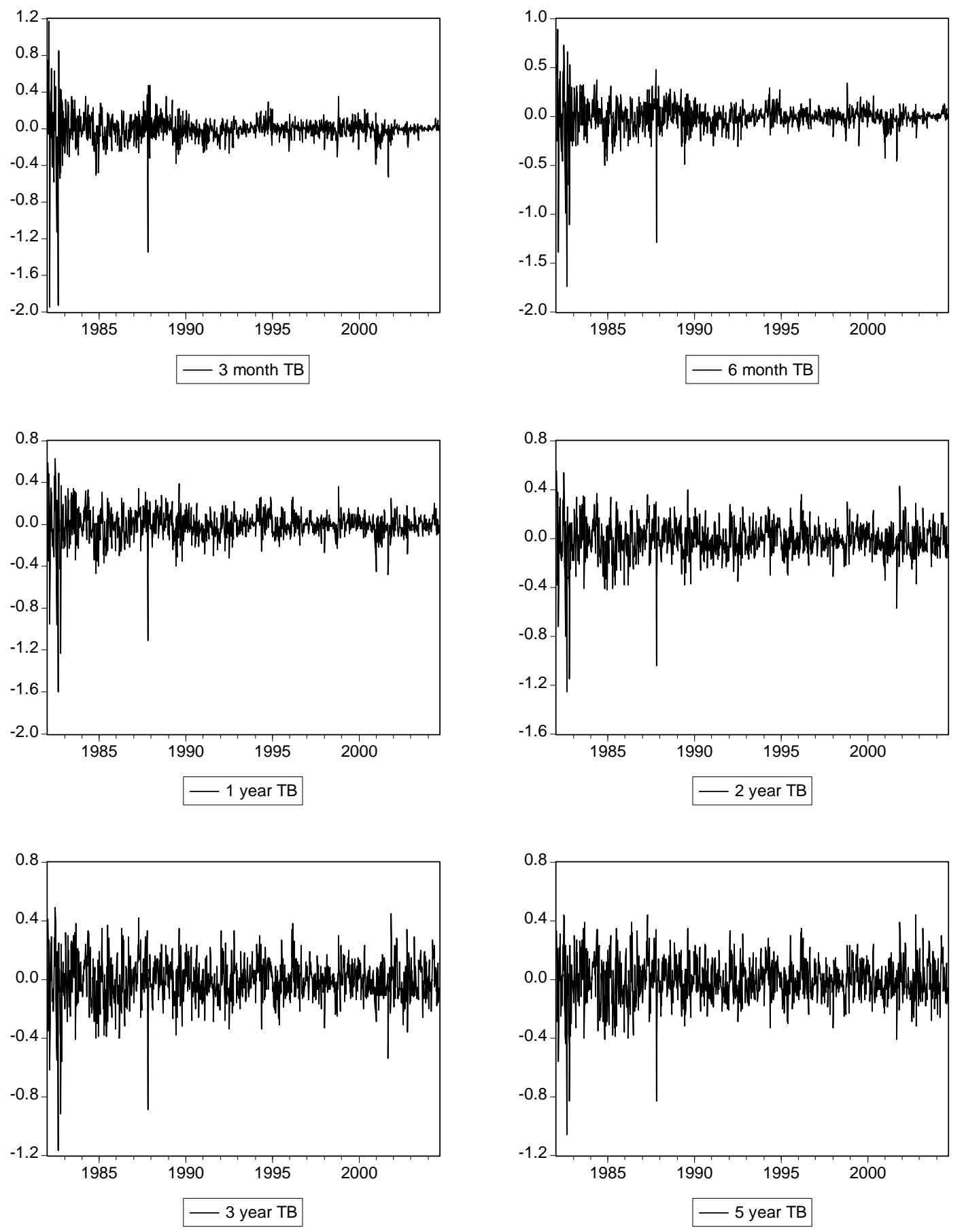
Figure 2: First Differences of Weekly Yields for 12 Debt Instruments (continued)
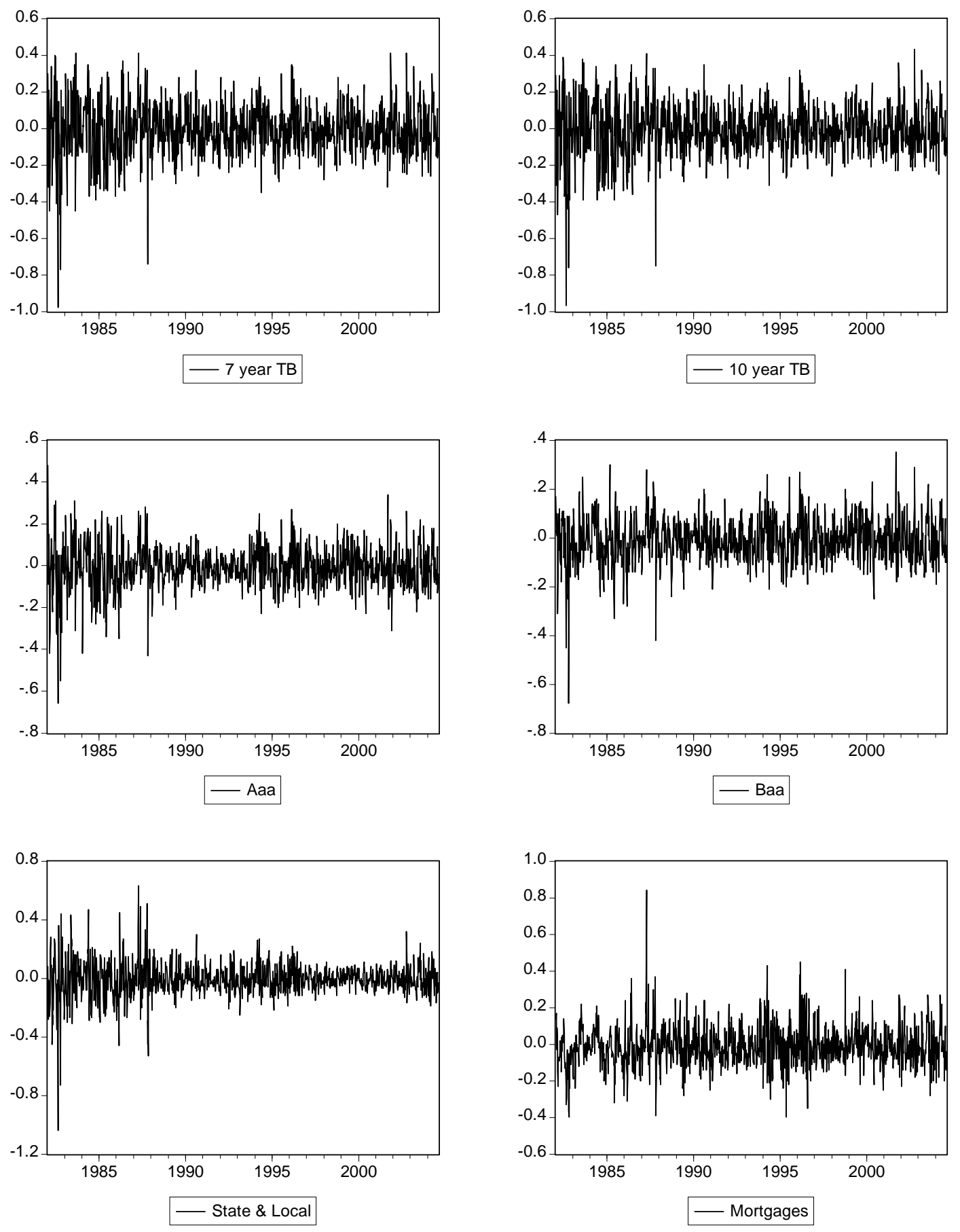
Figure 3: Sample Volatility for the First Differences of 12 Debt Instruments Weekly Yields
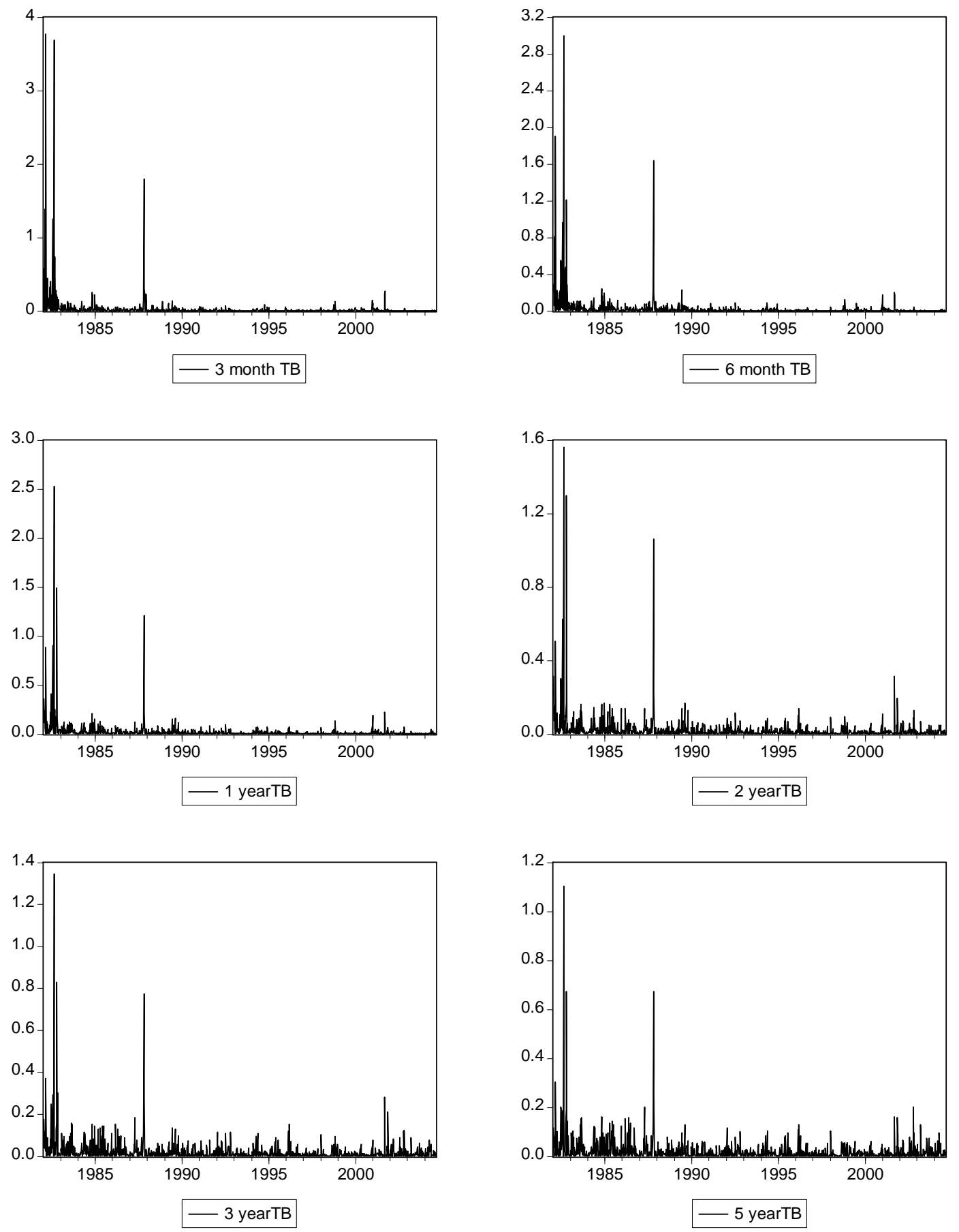
Figure 3: Sample Volatility for the First Differences of 12 Debt Instruments Weekly Yields (continued)
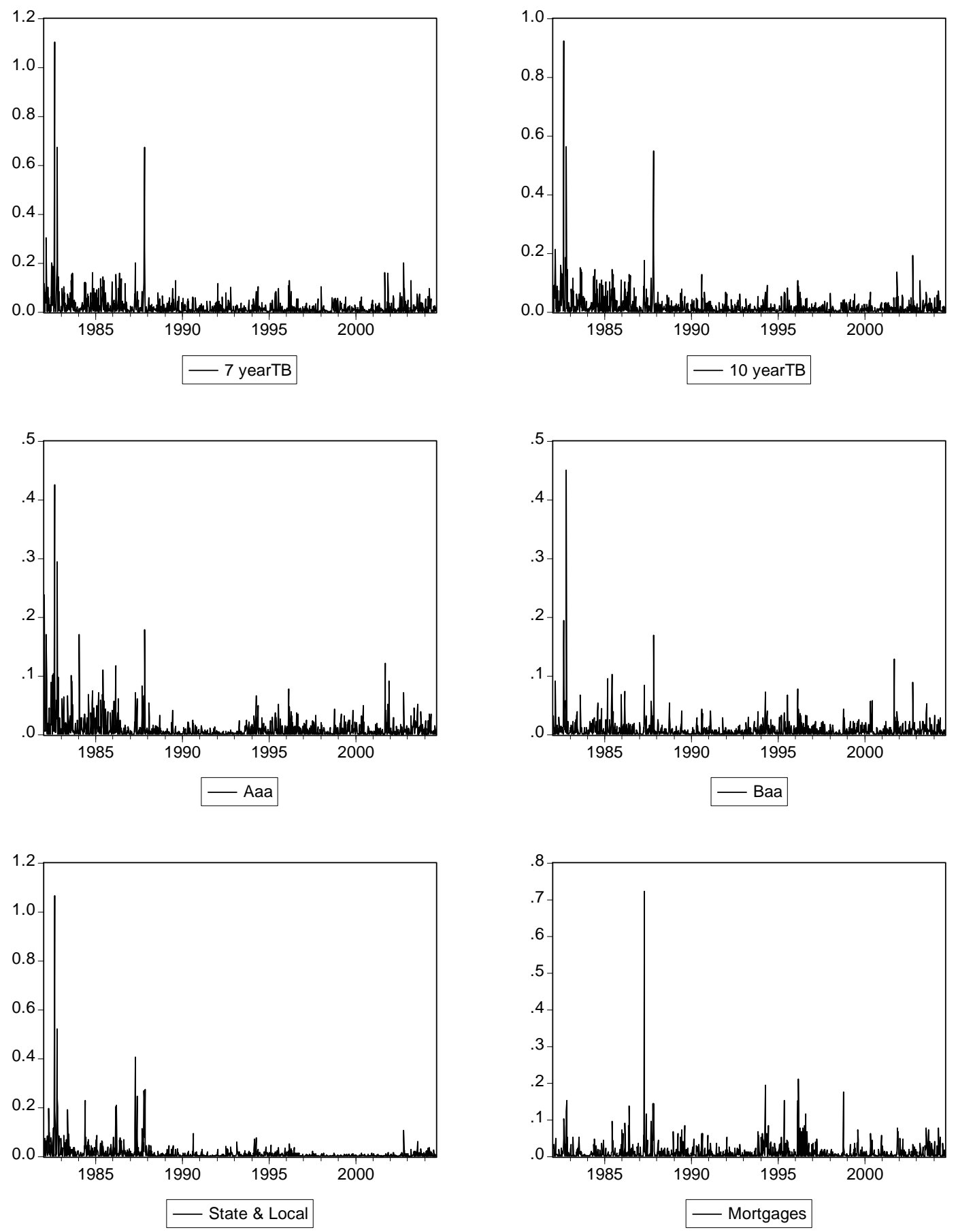
Figure 4: GARCH(1,1) Volatility for the First Differences of 12 Debt Instruments Weekly Yields
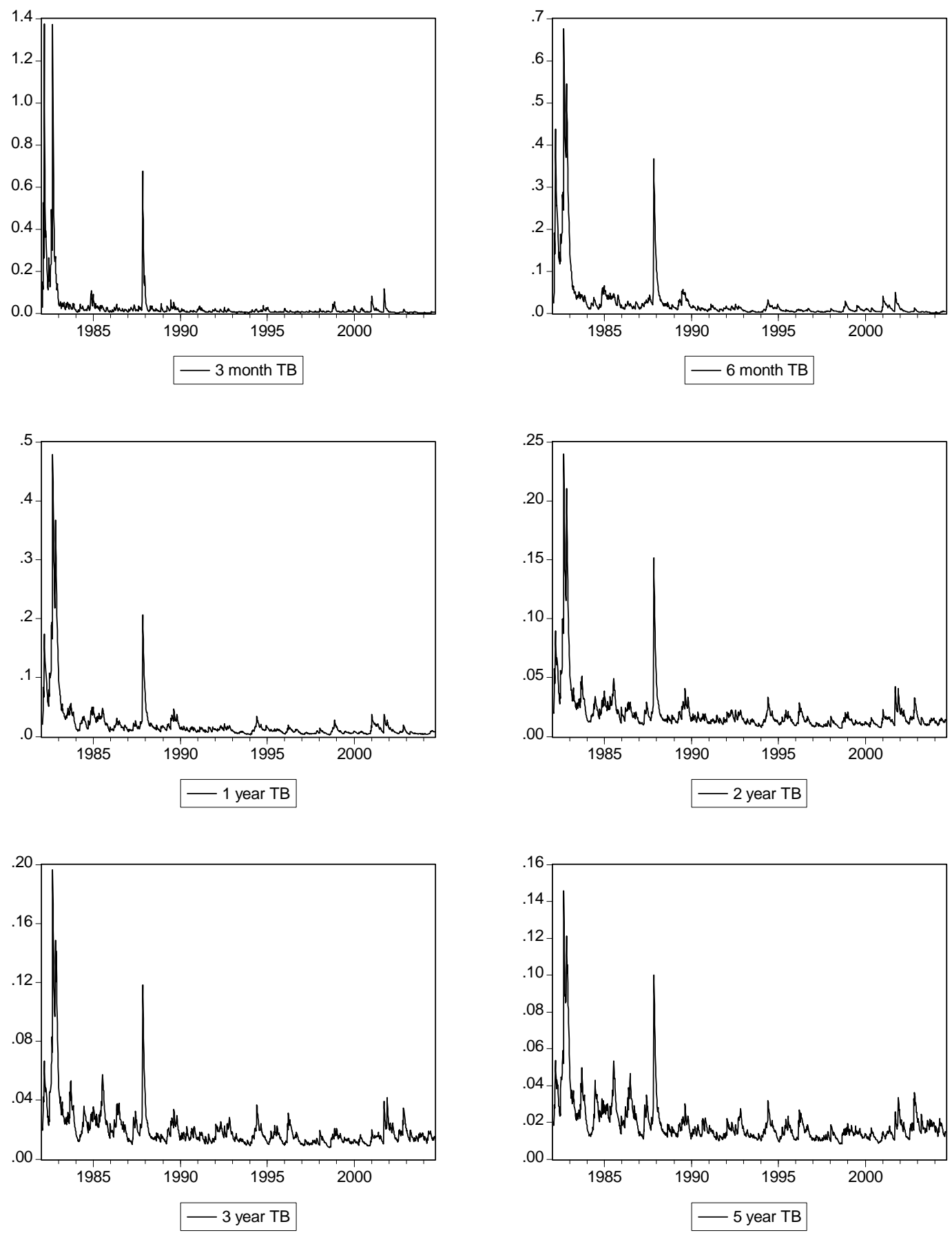
Figure 4: GARCH(1,1) Volatility for the First Differences of 12 Debt Instruments Weekly Yields (continued)
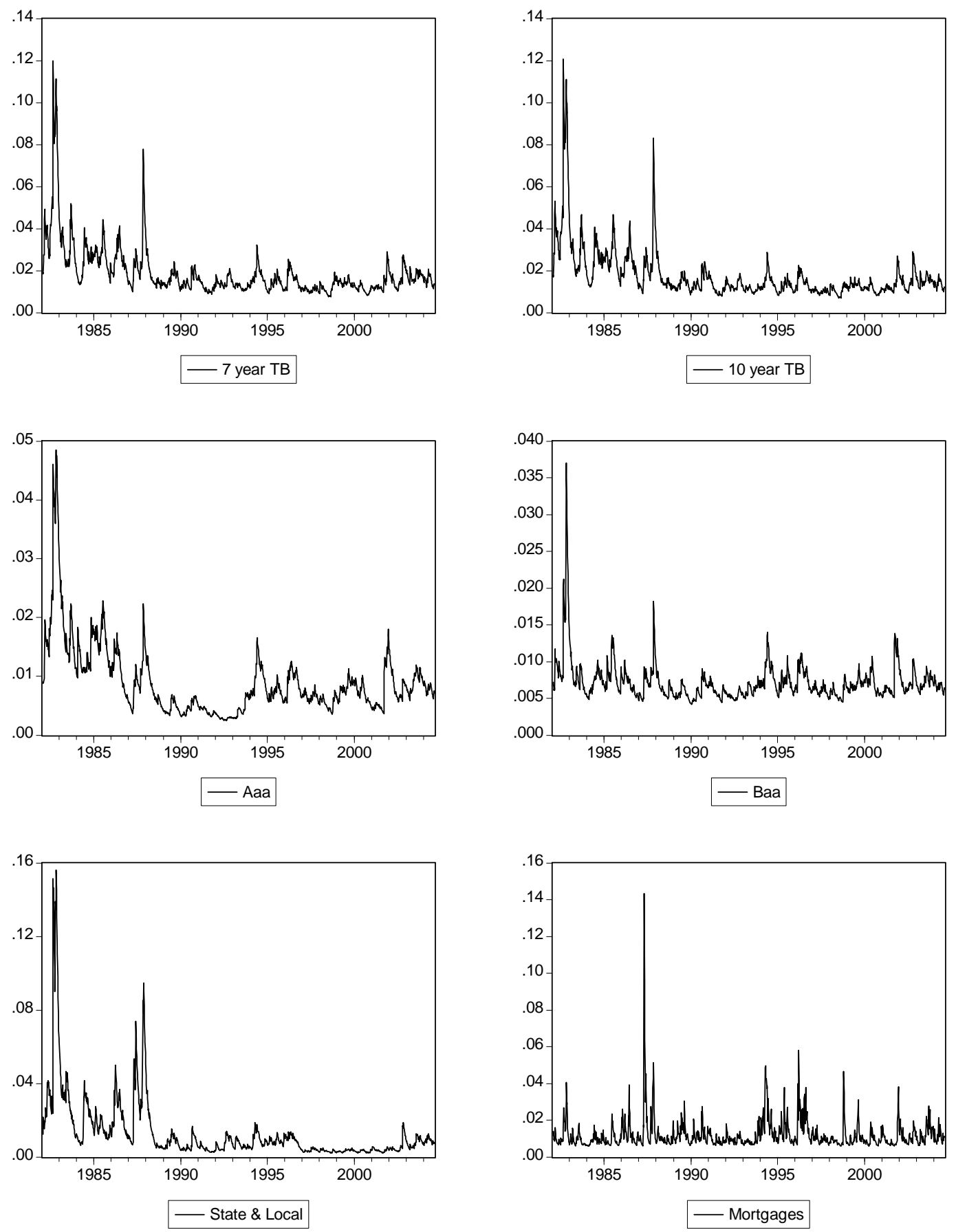

45 